\title{
Income Inequality Predicts Competitiveness and Cooperativeness at School
}

\begin{abstract}
Nicolas Sommet ${ }^{1}$, David L. Weissman ${ }^{2}$, and Andrew J. Elliot ${ }^{2}$
${ }^{1}$ Swiss National Centre of Competence in Research LIVES, University of Lausanne

${ }^{2}$ Department of Psychology, University of Rochester
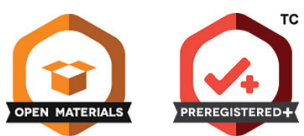

Competitiveness and cooperativeness are important predictors of social and learning outcomes at school. Drawing on evidence suggesting that contexts with high income inequality foster an ethos of competitiveness and inhibit cooperativeness in the economic environment, we examine whether income inequality is also associated with more competitiveness and less cooperativeness in the academic environment. We conducted four preregistered studies to test this idea. In Study 1, analysis of the OECD PISA 2018 data set $(\approx 500,00015$-year-old students from 75 countries) revealed that students from economically unequal countries perceive their schoolmates as more competitive and less cooperative. In Study $2 \mathrm{a}$ and $2 \mathrm{~b}$, analysis of the PISA $2003(250,000+$ students from 38 countries) and PISA $2000(75,000+$ students from 32 countries) data sets revealed that students from unequal countries are themselves more competitive and, surprisingly, also more cooperative. Follow-up analyses resolved this apparent paradox, showing that students from unequal countries are oriented toward instrumental rather than intrinsic cooperativeness (i.e., using cooperation as a strategic tool to achieve academic success rather than for the enjoyment of the activity itself). Study 3 offers a conceptual experimental replication $(\approx 850$ young adults imagining going back to school) and indicates that induced income inequality (a) increases perceived competitiveness, (b) decreases perceived cooperativeness, (c) prompts an orientation toward competitiveness, and (d) prompts an orientation toward instrumental rather than intrinsic cooperativeness. Results are discussed in relation to the multidisciplinary literatures on the psychology of income inequality, the selective function of school systems, coopetition, self-determination, and cooperative learning.
\end{abstract}

\section{Educational Impact and Implications Statement}

Individuals residing in places with high income inequality have been shown to compete more fiercely for status and cooperate less. In this research, we examine whether this phenomenon also applies to students at school. Analyses of three OECD PISA data sets $(\approx 850,000$ students from a total of $75+$ countries observed in 2018, 2003, and 2000) show that 15-year-old students from economically unequal countries (a) perceive their schoolmates as more competitive and less cooperative and (b) are more competitive and more strategically cooperative (i.e., they use cooperation as a tool to achieve academic success). An experiment manipulating income inequality ( $\approx 850$ young adults) led to the same conclusions. Taken together, our results suggest that income inequality fosters an ethos of competitiveness among the workforce of tomorrow.

Keywords: income inequality, social perception, academic motivation, competitiveness, cooperativeness Supplemental materials: https://doi.org/10.1037/edu0000731.supp

Nicolas Sommet (D) https://orcid.org/0000-0001-8585-1274

David L. Weissman (D) https://orcid.org/0000-0002-0778-1992

Andrew J. Elliot (D) https://orcid.org/0000-0002-1664-6426

This work was funded by a SNSF Ambizione fellowship granted to Nicolas Sommet (PZ00P1_185979). The authors declare no competing interests.

Preregistration documents, complete materials, raw economic/experimental data (or instructions to retrieve the secondary survey data), and Stata scripts and $\log$ files reproducing the findings are available via the OSF: https://osf .io/mz3tn/

II The data are available at https://osf.io/mz3tn/

- The experiment materials are available at https://osf.io/mz3tn/

The preregistered design is accessible at https://osf.io/mz3tn/

Correspondence concerning this article should be addressed to Nicolas Sommet, Swiss National Centre of Competence in Research LIVES Université de Lausanne, Bâtiment Géopolis, Bureau \#5785, Quartier UNIL-Mouline, Switzerland. Email: Nicolas.Sommet@unil.ch 
The extent to which students perceive their classmates as competitive or cooperative, and their own orientations toward competitiveness and cooperativeness, are important predictors of social and learning outcomes (for reviews, see Butera et al., 2021; Elliot, 2020; Johnson \& Johnson, 2021). Existing research on predictors of competitiveness and cooperativeness at school focus mainly on personal factors (e.g., social comparison tendencies), relational factors (e.g., relationship closeness), and task-based factors (e.g., incentive structures; for reviews see Garcia et al., 2013; Schneider et al., 2011). Herein we adopt a broader perspective and focus on a higher-level, macroeconomic factor: national income inequality.

Over the past decade, social scientists have begun to thoroughly investigate how residing in economically unequal contexts affects psychological outcomes (for a review, see Buttrick \& Oishi, 2017). A mounting body of evidence indicates that income inequality fosters an ethos of competitiveness in the economic environment (Rodríguez-Bailón et al., 2020) whereby individuals are prone to vie against one another for wealth/status (Payne et al., 2017; Walasek \& Brown, 2015) and cooperate less (Nishi et al., 2015). In the present research, we investigate whether this phenomenon also occurs in the academic environment, before individuals enter the labor market. Specifically, we examine the question: Is income inequality associated with more competitiveness and less cooperativeness at school?

\section{Competitiveness and Cooperativeness at School}

Competitiveness and cooperativeness at school can be conceptualized in two different ways: (a) as a characteristic of the perceived academic environment (perceived competitiveness and cooperativeness), and (b) as a characteristic of students (their orientation toward competitiveness and cooperativeness; Connelly et al., 2014). Perceived competitiveness and cooperativeness represent subjective construals of the competitive or cooperative nature of the achievement setting (Ames \& Archer, 1988; Deutsch, 1949; Karabenick, 1994), whereas orientations toward competitiveness and cooperativeness ${ }^{1}$ represent personal preferences to compete or cooperate with others in achievement settings (Horney, 1937/ 2013; Smither \& Houston, 1992; Spence \& Helmreich, 1983). Notably, these two theoretical constructs are interrelated. Perceiving others as being oriented toward competitiveness or cooperativeness influences one's own orientations via motivational contagion processes (e.g., for competitiveness, see King \& Mendoza, 2020; for cooperativeness, see Dik \& Aarts, 2007). Conversely, being oriented toward competitiveness or cooperativeness influences the perceptions of others' orientations via social projection processes (e.g., for competitiveness, see Elliot et al., 2018; for cooperativeness, see Krueger et al., 2012).

Competitiveness and cooperativeness shape how students navigate the social context of schools. On the one hand, competitiveness creates negative social interdependence in which the academic success of others is seen as an impediment to one's own success; as such, it is not surprising that competitiveness often predicts undesirable peer interaction outcomes, such as intolerance for disagreements, information withholding, and tactical deception (for a review, see Butera et al., 2021). On the other hand, because cooperativeness creates positive social interdependence in which the academic success of others is seen as a catalyst of one's own success, it is also not surprising that interventions designed to increase cooperativeness have been found to predict positive peer interaction outcomes, such as esprit de corps, social cohesiveness, and support for others (for a meta-analysis, see Roseth et al., 2008). However, based on Piagetian and Vygotskian social constructivist perspectives in which peer interactions are considered vital to the development of intersubjectivity and the promotion of learning (Tenenbaum et al., 2020), researchers have long posited that competitiveness and cooperativeness are detrimental and beneficial for achievement, respectively (for early work, see Johnson \& Johnson, 1974). However, current meta-analytic evidence suggests that competitiveness may exert both negative and positive effects on achievement (Murayama \& Elliot, 2012), whereas cooperative learning procedures do exert positive effects on achievement (Kyndt et al., 2013), particularly for disadvantaged students (Zeneli et al., 2016).

Given how important competitiveness and cooperativeness are to social and learning outcomes, considerable research effort has been devoted to examining their predictors (Schneider et al., 2011). Evidence from multiple lines of research demonstrates that competitiveness and cooperativeness are predicted by a number of factors at the person-level (e.g., heritability; Cesarini et al., 2008; Olson et al., 2001), family-level (e.g., parents' socioeconomic status; Almås et al., 2016; Bauer et al., 2014), dyad-level (e.g., samesex vs. mixed-sex interactions, Balliet et al., 2011; Sutter et al., 2009), group-level (e.g., small-sized vs. medium-sized working groups; Alencar et al., 2008; Garcia et al., 2013), teacher-level (e.g., evaluation-related instructional practices; Meece et al., 2006; Slavin, 2017), classroom-level (e.g., autonomy-supportive classroom climate; Lerdpornkulrat et al., 2018; Owens \& Barnes, 1982), and school-level (e.g., private vs. public schools; Marks, 2009). In the present research, we adopt a different, broader perspective, and investigate whether competitiveness and cooperativeness are also predicted by a particular country-level factor: income inequality.

\section{Income Inequality, Competitiveness, and Cooperativeness}

Across Organization for Economic Cooperation and Development (OECD) countries, the income of the lower and middle classes has increased modestly over the past 30 years, while the income of the upper class has surged to historic highs (OECD, 2019d). These differences have led to a return to levels of income inequality not seen since the postwar era (Atkinson, 2003). Given the scale of this phenomenon, scholars have raised the question of the psychological consequences of income inequality, in particular its influence on the way that people perceive and interact with others (for a review, see Rodríguez-Bailón et al., 2020).

\footnotetext{
${ }^{1}$ Orientations toward competitiveness and cooperativeness are arguably akin to the well-established concept of trait competitiveness (Brown et al., 1998) and the emerging concept of trait cooperativeness (Thielmann \& Hilbig, 2014; see also Cloninger, 1993), respectively. In the present work, we favor the term "orientation" over "trait," because traits are more likely to be seen as cross-situational, enduring dispositions, despite the fact that personality traits are known to be especially unstable during adolescence (Borghuis et al., 2017; the target populations for Studies 1, 2a and 2b) and early adulthood (Bleidorn, 2015; the target population for Study 3).
} 


\section{Income Inequality, Competitiveness, and Cooperativeness in the Economic Environment}

Income inequality has long been thought to increase the level of economic segmentation (Wilkinson, 1997). When income inequality is high, the poor and the rich are further apart on the pay scale, which makes standards of income comparison more salient. Accordingly, individuals feel more concerned about their relative income (Präg et al., 2014), show greater attention to markers of wealth like luxury brands (Walasek et al., 2018; Walasek \& Brown, 2015, 2016), and are particularly vulnerable to the negative psychological effects of having a disadvantaged socioeconomic status (Schneider, 2019; Sommet et al., 2018).

As income inequality heightens the subjective importance of status, it promotes the perception that everyone around oneself competes for status and cooperates less. Observational (i.e., nonexperimental) evidence indicates that people residing in more unequal areas perceive their fellow residents as being more prone to competitiveness (Sommet et al., 2019), and that income inequality can disrupt the social fabric and break the norms of reciprocity that facilitate cooperation (Kawachi \& Kennedy, 1999; but see Kim et al., 2021). Experimental evidence confirms this twofold tendency: When participants are asked to imagine living in a society with high rather than low levels of income inequality, they picture their fellow inhabitants as being more likely to care about personal success, social recognition, and competitiveness, rather than the welfare of others, social justice, and cooperativeness (Cheng et al., 2021; Melita et al., 2021; Sánchez-Rodríguez et al., 2020; Sánchez-Rodríguez et al., 2019).

The way that people from unequal contexts perceive the motivation of others also affects their own orientation toward competitiveness and cooperativeness. As people residing in more unequal areas perceive others as more oriented toward competitiveness, they come to endorse the competitive goal of being richer than others (or, at least, not being poorer than others; Sommet et al., 2019). Converging evidence from a broad range of disciplines reveals that people in contexts with high income inequality make riskier financial decisions (Mishra et al., 2015; Payne et al., 2017), borrow more money (Christen \& Morgan, 2005; Fligstein et al., 2017), and work longer hours (Alexiou \& Kartiyasa, 2020; Bowles \& Park, 2005), arguably to keep up with the economic competition (Paskow et al., 2013; see also Du, Chen, Li, et al., 2021). Conversely, people in contexts with low income inequality have a greater dislike for competitive groups (Durante et al., 2013), a higher level of agreeableness (a personality trait associated with cooperativeness; de Vries et al., 2011), and an increased tendency to cooperate in economic games (Côté et al., 2015; Nishi et al., 2015; Rosenbaum et al., 2016; but see Schmukle et al., 2019). Herein we argue that income inequality is not only associated with more competitiveness and less cooperativeness among economic agents in the economic environment, but also among the workforce of tomorrow in the academic environment.

\section{Income Inequality, Competitiveness, and Cooperativeness in the Academic Environment}

From a sociological perspective, school systems serve two main functions: (a) an educational function (preparing all students to be contributing members of society), and (b) a selective function (directing the best students to the best positions in society; Darnon et al., 2009; Dornbusch et al., 1996). To fulfill the selective function, schools assess, compare, and sort students according to meritocratic principles (Batruch, Autin, \& Butera, 2019). In doing so, schools rely on several institutional tools such as grading (Pulfrey et al., 2011), pass/fail-criteria (Meyer et al., 2009), or ranking (Sommet et al., 2013). These tools are used to stream students into educational tracks with different requirements (Batruch, Autin, Bataillard et al., 2019), that in turn lead to curricula of different durations (Chmielewski, 2014), that prepare individuals for careers with different levels of income (OECD, 2019a). As such, schools have been compared with social sorting machines that gatekeep "access to highly compensated, high-status occupations" (Domina et al., 2017, p. 316).

From there, it is easy to imagine how income inequality may structure the academic competition for positions in stratified societies: When the gap between low- and high-income groups widens, so does the pressure to obtain the best grades, to be admitted to the most prestigious universities, and to join the highest income group possible. When income inequality is high, students may realize by themselves the critical importance of academic competition, or - perhaps more plausibly - their family members might change their emphasis, discourse, and/or socialization practices to stress the importance of getting ahead of the academic competition (for work showing how income inequality affects parenting style, see Doepke \& Zilibotti, 2019). It is also possible that school staff and, in particular, teachers (the main agents of school systems) may adopt normative assessment practices rather than cooperative learning practices (e.g., using reward focused on individual outcomes rather than team efforts) because they feel it will help their students succeed in high-stake tests, and reach the highest possible rung of the social ladder (for a review on teachers as institutional gatekeepers, see Butera et al., 2021, for a review on the effect of highstake testing on teaching, see Wei, 2017). Importantly, these practices go hand in hand with encouraging (or emphasizing) social comparison, relative performance, and individual achievement (for a review on classroom goal structure, see Meece et al., 2006), which are noticed by students and shape their motivations (Bardach et al., 2020, 2021). Thus, when income inequality is high, it is possible that students will perceive more competitiveness and less cooperativeness in their school and become more competitive and less cooperative with one another.

\section{Overview and Hypotheses}

We conducted four preregistered studies to test the relationships between income inequality and competitiveness/cooperativeness at school. The first three studies used observational data from the OECD Program for International Student Assessment (PISA) studies, a series of cross-national surveys of representative national populations of 15-year-old students. Specifically, Study 1 used the data from PISA 2018 (approximately half a million students from 75 countries) to test the prediction that national income inequality is associated with the perception that one's schoolmates are more competitive (Hypothesis 1A) and less cooperative (Hypothesis 1B). Studies $2 \mathrm{a}$ and $2 \mathrm{~b}$ used the data from PISA 2003 and PISA 2000 (approximately a third of a million students from 38 and 32 
countries, respectively) to test the prediction that national income inequality is associated with a stronger orientation toward competitiveness (Hypothesis 2A) and a weaker orientation toward cooperativeness (Hypothesis 2B). We choose to work with PISA 2018, 2003, and 2000 because they are the only three PISA studies that assess perceptions of or orientations toward both competitiveness and cooperativeness, and we wanted to run as many large-scale replications as possible.

The fourth study used experimental data. Participants 18 to 29 years old were asked to imagine going back to school in a society with either high income inequality (experimental condition) or low income inequality (control condition). Our aim was to conceptually replicate the effects of income inequality on perceived competitiveness and cooperativeness observed in Study 1 , as well as the effects of income inequality on orientations toward competitiveness and cooperativeness observed in Studies $2 \mathrm{a}$ and $2 \mathrm{~b}$.

For all studies, the analyses were planned a priori (unless otherwise specified), and all data exclusions and variables analyzed are reported. Preregistration documents, complete materials, raw economic/experimental data (or instructions to retrieve the secondary survey data), and Stata scripts and log files reproducing the findings are on the OSF: https://osf.io/mz3tn/.

\section{Study 1 (PISA 2018): Income Inequality and Perceived Competitiveness/Cooperativeness}

In Study 1, we aimed to test the following preregistered hypotheses: "Income inequality is a positive predictor of perceived competitiveness (Hypothesis 1A) and a negative predictor of perceived cooperativeness (Hypothesis 1B)" (see "Preregistration (PISA) 2018.pdf" on https://osf.io/mz3tn/).

\section{Method}

\section{Participants}

We used the data from PISA 2018 to test our hypotheses. As indicated in the preregistration, we retained all countries with nonmissing values for income inequality (100\% of countries) and all students with nonmissing values for perceived competitiveness and/or cooperativeness ( $81.11 \%$ of students). The final sample comprised 496,455 students from 20,643 schools and 75 countries (for sample characteristics, see Table 1). The sample size was sufficient to detect a small-sized effect of income inequality with a power of $.99+$ (for the sensitivity analysis, see the online supplemental materials [p. ii]).

\section{Variables}

Income Inequality. We used the Gini coefficient, a commonly used measure of income inequality that can range from 0 (perfect equality: Everyone in the country has the same income) to 1 (perfect inequality: A single person in the country has all of the income). We acquired the Gini coefficients for each country from the World Income Inequality Database (WIID; UNU-WIDER, 2021). As indicated in the preregistration, we used the 2018 Gini coefficients or the next most recent estimates if the 2018 estimates were not available $(M=.35 \pm .08)$.
Perceived Competitiveness and Cooperativeness. We used PISA's four-item measures of perceived competitiveness (e.g., "[In my school] it seems that students are competing with each other") and cooperativeness (e.g., "[In my school] it seems that students are cooperating with each other"; response options ranged from $1=$ Not at all true to $4=$ Extremely true). The PISA team adapted these measures from Murayama and Elliot (2012) and described them as assessing how much "students perceive that other students at the school compete with each other" and "cooperate with each other," respectively (see OECD, 2019b, p. 120). We averaged the four competitiveness items to obtain a measure of perceived competitiveness $(\bar{\alpha}=.82 \pm .04, M=2.56 \pm .72$, $\left.\mathrm{ICC}_{\text {country }}=.06[.04, .08], \mathrm{ICC}_{\text {country|school }}=.09[.08, .11]\right)$ and the four cooperativeness items to obtain a measure perceived cooperativeness $\left(\bar{\alpha}=.85 \pm .55, M=2.69 \pm .73, \mathrm{ICC}_{\text {country }}=.04[.03\right.$, $\left..08], \mathrm{ICC}_{\text {country|school }}=.09[.08 .10]\right) .^{2}$ The correlation between the two measures was $r=.27, p<.001 .^{3}$

\section{Results}

\section{Overview of Analyses}

We treated students (level-1 units) as nested in schools (level2 units) and countries (level-3 units). We regressed each outcome (perceived competitiveness or cooperativeness) on income inequality while excluding or including a preregistered set of four commonly used student-level control variables (age, sex, origin, social class background) and five country-level potentially confounding variables (national population, GDP, poverty, unemployment, and expenditure on education). We used multiple imputation by chained equations (MICE) with 10 imputed data sets to account for missing values on the control variables. Tables 2 and 3 present the full results and regression equation for the main analyses. ${ }^{4}$

\section{Main Preregistered Analyses}

Consistent with Hypothesis 1A, the higher the income inequality, the higher the perceived competitiveness, $\beta=.07[.02$, $.13], p=.008$, and $\beta_{\mathrm{c}}=.08[.01, .15], p_{\mathrm{c}}=.019$ (in this and the subsequent studies, subscript $c$ identifies statistical estimates pertaining to the models including control variables). Moreover, consistent with Hypothesis $1 \mathrm{~B}$, the higher the income inequality, the lower the perceived cooperativeness, $\beta=-.04[-.09, .01]$, $p=.082$, and $\beta_{\mathrm{c}}=-.07[-.13,-.02], p_{\mathrm{c}}=.009$ (for a graphical representation of the findings, see Figure 1). In this and the other PISA studies, we preregistered additional analyses testing the

\footnotetext{
${ }^{2} \bar{\alpha}$ refers to the pooled within-country Cronbach's alpha; $\mathrm{ICC}_{\text {country }}$ refers to the level-3 intraclass correlation coefficient (e.g., $6 \%$ of the variation in perceived competitiveness is explained by between-country differences); ICC $_{\text {country|school }}$ refers to the level-2 intraclass correlation coefficient (9\% of the variation in perceived competitiveness within countries is explained by between-school differences); numbers in brackets represent $95 \%$ confidence intervals.

${ }^{3}$ In this and the subsequent observational studies, we used clusteradjusted standard errors to calculate the $p$-value of the correlation coefficient.

${ }^{4}$ As indicated in the preregistration, we used Cook's distance to identify highly influential higher-level observations. In this and the two subsequent studies, the results were the same with and without influential countries.
} 
Table 1

Studies 1 and Studies 2a-2b: Description of the PISA 2018, 2003, and 2000 Samples and Variables

\begin{tabular}{lccc}
\hline \multicolumn{1}{c}{ Variable } & Study 1 PISA 2018 & Study 2a PISA 2003 & Study 2b PISA 2000 \\
\hline Student-level sample characteristics & & & \\
$M$ age & $15.79 \pm 0.29$ & $15.80 \pm 0.28$ & $15.67 \pm 0.34$ \\
Percent of boys & $50.29 \%$ & $49.24 \%$ & $48.78 \%$ \\
Percent of native students & $87.97 \%$ & $91.64 \%$ & $91.42 \%$ \\
Percent with $\geq 1$ college-educated parent(s) & $58.56 \%$ & $42.33 \%$ & $62.58 \%$ \\
Country-level sample mean characteristics & & & \\
National population (millions) & $53.10 \pm 167.48$ & $45.68 \pm 67.04$ & $37.52 \pm 167.48$ \\
GDP per capita (2010 USD, thousands) & $26.26 \pm 23.76$ & $31.30 \pm 22.68$ & $29.92 \pm 23.49$ \\
Unemployment rate & $6.61 \% \pm 4.30$ & $8.55 \pm 6.22$ & $8.02 \% \pm 6.07$ \\
Poverty ratio at 2011 PPP \$1.90 a day & $0.99 \% \pm 1.48$ & $2.12 \pm 4.96$ & $1.62 \% \pm 3.35$ \\
Share of GDP spent on education & $4.57 \% \pm 1.38$ & $4.83 \pm 1.41$ & $4.72 \% \pm 1.27$ \\
\hline
\end{tabular}

Note. Country-level control variable estimates were collected from the World Bank. GDP = gross domestic product; PPP = purchasing power parity.

downstream effects of income inequality via competitiveness and cooperativeness on various outcomes. The results-which were inconclusive-are presented in the online supplemental materials [p. iii-v].

\section{Additional Nonpreregistered Analyses}

We did not anticipate one issue in the preregistration: When the 2018 income inequality estimates were not available, the next most recent estimates were sometimes quite far in the past (for about $20 \%$ of the countries, they were older than two years). We therefore repeated the analyses without using income inequality estimates older than two years (61 of 75 countries were retained in the analyses). We observed the same pattern of findings (for the full results, see Table S1) and we fixed the problem in Studies $2 \mathrm{a}$ and $2 \mathrm{~b}$ by preregistering that we would not use income inequality estimates older than two years.

\section{Discussion}

In Study 1, we showed that income inequality is associated with the perception that one's schoolmates are more competitive (consistent with preregistered Hypothesis 1A) and less cooperative (consistent with preregistered Hypothesis 1B). In Studies $2 \mathrm{a}$ and $2 \mathrm{~b}$, we examined whether income inequality is associated with a different orientation toward competitiveness and cooperativeness. Study 2 a used the data from PISA 2003, a survey that focused on a specific subject area, namely mathematical literacy; hence, it included assessments of domain-specific orientations toward competitiveness and cooperativeness. However, Study 2b used the data from PISA 2000, a survey that did not focus on any specific subject area; hence, it included assessments of domain-general orientations toward competitiveness and cooperativeness. Note that the differentiation between domain-specific and domain-general outcomes was not theoretically driven, but rather was a mere function of the fact that the PISA team decided to change the focus of their assessment. However, given our belief that income inequality fosters a general ethos of competitiveness and inhibits cooperativeness across the board, we expected both studies to produce similar results.

\section{Studies 2a (PISA 2003) and 2b (PISA 2000): Income Inequality and Orientation Toward Competitiveness/ Cooperativeness}

In Studies $2 \mathrm{a}$ and $2 \mathrm{~b}$, we aimed to test the following preregistered hypotheses: "Income inequality is a positive predictor of competitiveness [Hypothesis 2A] and a negative predictor of cooperativeness [Hypothesis 2B]" (see "Preregistration (PISA 200300).pdf" on https://osf.io/mz3tn/).

\section{Method \\ Participants}

We used the data from PISA 2003 (Study 2a) and PISA 2000 (Study $2 \mathrm{~b}$ ) to test our hypotheses. As indicated in the preregistration, we retained all countries with nonmissing values for income inequality ( $96.34 \%$ of countries across studies) and all students with nonmissing values for competitiveness and/or cooperativeness orientation $(86.26 \%$ of students across studies). The final samples comprised 259,759 students from 9,907 schools and 38 countries (Study 2a) and 77,498 students from 5,440 schools and 32 countries (Study 2b; for sample characteristics, see Table 1). The sample sizes were sufficient to detect a small-sized effect of income inequality with a power of .85 and .74 , respectively (for the sensitivity analyses, see online supplemental materials [p. ii]). ${ }^{5}$

\section{Variables}

Income Inequality. We again acquired the Gini coefficients for each country from the WIID. As indicated in the preregistration, we used the Gini coefficients of the same year as the PISA data collection; if they were not available, we used the next most recent estimates from either of the two preceding years (Study 2a: $M=.35 \pm .08$; Study $2 \mathrm{~b}: M=.36 \pm .08$ ).

Competitiveness and Cooperativeness Orientations. Our hypotheses were not only tested using domain-specific competitiveness

\footnotetext{
${ }^{5}$ Given concerns regarding statistical power (Study $2 \mathrm{~b}$ was slightly below the conventional $80 \%$ threshold), we preregistered that we might append the PISA 2000 data set to the PISA 2003 data set and use this appended data set in a single study (instead of running two separate studies). Using the appended data set to estimate the pooled within-data set effects of income inequality on competitiveness and cooperativeness led to the same conclusions as the main analyses (all $p \mathrm{~s} \leq .023$ ).
} 
Table 2

Studies 1 and 2a-2b: Standardized Coefficients and 95\% CIs of the Multilevel Models Estimating the Effects (Highlighted in Bold) of Income Inequality on Perceived Competitiveness (Study 1) and Domain-Specific (Study 2a) or Domain-General (Study 2b) Competitiveness Orientation

\begin{tabular}{|c|c|c|c|c|c|c|}
\hline \multirow{3}{*}{$\begin{array}{c}\text { Measure } \\
\text { Number of students / schools / countries } \\
\text { Without controls }\end{array}$} & \multicolumn{2}{|c|}{ Study 1 (PISA 2018) } & \multicolumn{2}{|c|}{ Study 2a (PISA 2003) } & \multicolumn{2}{|c|}{ Study 2b (PISA 2000) } \\
\hline & \multicolumn{2}{|c|}{$490,106 / 20,630 / 75$} & \multicolumn{2}{|c|}{$259,070 / 9,907 / 38$} & \multicolumn{2}{|c|}{$77,391 / 5,440 / 32$} \\
\hline & $\beta$ & $95 \% \mathrm{CI}$ & $\beta$ & $95 \% \mathrm{CI}$ & $\beta$ & $95 \% \mathrm{CI}$ \\
\hline Gini coefficient $-G$ & $.07 * *$ & {$[.02, .13]$} & $.17 * * *$ & {$[.08, .26]$} & $.12 *$ & {$[.02, .22]$} \\
\hline Student residual variance $-\operatorname{var}\left(e_{\mathrm{ijk}}\right)$ & .24 & {$[.21, .29]$} & .28 & {$[.22, .35]$} & .28 & {$[.22, .36]$} \\
\hline School residual variance $-\operatorname{var}\left(u_{0 \mathrm{jk}}\right)$ & .19 & {$[.19, .19]$} & .21 & {$[.20, .21]$} & .18 & {$[.16, .19]$} \\
\hline Country residual variance $-\operatorname{var}\left(v_{00 \mathrm{k}}\right)$ & .98 & {$[.98, .98]$} & .98 & {$[.98, .98]$} & .99 & {$[.98, .99]$} \\
\hline With controls & $\beta$ & $95 \% \mathrm{CI}$ & $\beta$ & $95 \% \mathrm{CI}$ & $\beta$ & $95 \% \mathrm{CI}$ \\
\hline Gini coefficient $-G$ & $.08 *$ & {$[.01, .15]$} & $.10 *$ & {$[.01, .20]$} & $.16^{*}$ & {$[.01, .31]$} \\
\hline Age $-\mathrm{A}$ & $.01 * * *$ & {$[.01, .01]$} & $-.01 * * *$ & {$[-.02,-.01]$} & .00 & {$[-.01, .00]$} \\
\hline $\operatorname{Sex}(+0.5=$ boys $)-S$ & $.04 * * *$ & {$[.04, .05]$} & $.12 * * *$ & {$[.11, .12]$} & $.05 * * *$ & {$[.04, .05]$} \\
\hline Origin $(+0.5=$ native $)-O$ & .00 & {$[.00, .01]$} & $-.06^{* * *}$ & {$[-.06,-.05]$} & $-.02 * * *$ & {$[-.03,-.01]$} \\
\hline Social class background $(+0.5=$ high $)-S C$ & $.03 * * *$ & {$[.03, .04]$} & $.03 * * *$ & {$[.02, .03]$} & $.05 * * *$ & {$[.04, .05]$} \\
\hline National population $-P P$ & -.02 & {$[-.08, .04]$} & .05 & {$[-.06, .15]$} & -.02 & {$[-.11, .07]$} \\
\hline GDP per capita $(\operatorname{logs})-G D P$ & .02 & {$[-.04, .09]$} & -.03 & {$[-.16, .10]$} & $-.19 * * *$ & {$[-.31,-.08]$} \\
\hline Unemployment rate $-U$ & -.01 & {$[-.08, .06]$} & .11 & {$[-.01, .24]$} & -.09 & {$[-.24, .06]$} \\
\hline Poverty headcount ratio $-P$ & .01 & {$[-.05, .07]$} & -.05 & {$[-.16, .05]$} & .02 & {$[-.08, .12]$} \\
\hline Expenditure on education $-E$ & -.05 & {$[-.11, .01]$} & -.03 & {$[-.13, .07]$} & .05 & {$[-.04, .14]$} \\
\hline Country residual variance $-\operatorname{var}\left(v_{00 \mathrm{k}}\right)$ & .24 & {$[.20, .28]$} & .24 & {$[.19, .31]$} & .21 & {$[.16, .27]$} \\
\hline School-level residual variance $-\operatorname{var}\left(u_{0 \mathrm{jk}}\right)$ & .19 & {$[.18, .19]$} & .19 & {$[.19, .20]$} & .17 & {$[.16, .18]$} \\
\hline Student-level residual variance $-\operatorname{var}\left(e_{\mathrm{ijk}}\right)$ & .98 & {$[.98, .98]$} & .97 & {$[.97, .97]$} & .98 & {$[.98, .99]$} \\
\hline
\end{tabular}

Note. The multilevel regression equation is $Y_{\mathrm{ijk}}=B_{000}+B_{001} \times G_{\mathrm{k}}\left[+B_{100} \times A_{\mathrm{ijk}}+B_{200} \times S_{\mathrm{ijk}}+B_{300} \times O_{\mathrm{ijk}}+B_{400} \times S C_{\mathrm{ijk}}+B_{002} \times P P_{\mathrm{k}}+B_{003} \times\right.$ $\left.G D P_{\mathrm{k}}+B_{004} \times U_{\mathrm{k}}+B_{005} \times P_{\mathrm{k}}+B_{005} \times E_{\mathrm{k}}+\right] e_{\mathrm{ijk}}+u_{0 \mathrm{jk}}+v_{00 \mathrm{k}}, i=1,2, \ldots, N$ (participants), $j=1,2, \ldots, K$ (schools), $k=1,2, \ldots, L$ (countries); higher-class students have $\geq 1$ college-educated parent(s); student-level variables were standardized by dividing the mean-centered variable by the average within-country $S D$; for country-level variables, we used the between-country $S D$. GDP = gross domestic product.

$* p<.05$. ** $p<.01$. *** $p<.001$.

and cooperativeness orientations (Study 2a), but also using domain-general orientations (Study 2b).

Domain-Specific. In Study 2a, we used PISA's four-item measures of domain-specific orientations toward competitiveness (e.g., "In Mathematics, I always try to do better than the other students in my class") and cooperativeness (e.g., "In Mathematics, I enjoy helping others to work well in a group"; response options ranged from $1=$ Strongly disagree to $4=$ Strongly agree). The PISA team adapted these measures from Owens and Barnes (1992) and described them as assessing "preferences for competitive learning situation" and "cooperative learning situation," respectively (OECD, 2004 , p. 313). We averaged the four competitiveness items to obtain a measure of orientation toward competitiveness $(\bar{\alpha}=.82 \pm .03$, $M=2.63 \pm .64, \mathrm{ICC}_{\text {country }}=.10[.06, .14], \mathrm{ICC}_{\text {country } \mid \text { school }}=.14$ $[.10, .18])$ and the four cooperativeness items to obtain a measure of orientation toward cooperativeness $(\bar{\alpha}=.75 \pm .06, M=2.85 \pm .72$, $\left.\mathrm{ICC}_{\text {country }}=.08[.05, .13], \mathrm{ICC}_{\text {country } \mid \text { school }}=.11[.08, .15]\right)$. The correlation between the two measures was $r=.32, p<.001$.

Domain-General. In Study 2b, we used PISA's five-item measures of domain-general orientations toward competitiveness (e.g., "I would like to be the best at something") and cooperativeness (e.g., "I like to help other people do well in a group"; response options ranged from $1=$ Disagree to $4=$ Agree $)$. As in Study 2a, the PISA team adapted these measures from Owens and Barnes (1992) and again described them as assessing "preferences for competitive learning" and "cooperative learning," respectively (OECD, 2003; p. 137). We averaged the five competitiveness items to obtain a measure of orientation toward competitiveness $\left(\bar{\alpha}=.76 \pm .05, M=2.77 \pm .55, \mathrm{ICC}_{\text {country }}=.06[.04, .09]\right.$, $\left.\mathrm{ICC}_{\text {country|school }}=.08[.04, .09]\right)$ and the five cooperativeness items to obtain a measure of orientation toward cooperativeness $(\bar{\alpha}=.64 \pm$ $.05, M=2.94 \pm .63, \mathrm{ICC}_{\text {country }}=.09[.06, .14], \mathrm{ICC}_{\text {country|school }}=.12$ $[.09, .17])$. The correlation between the two measures was $r=.25$, $p<.001$.

\section{Results}

\section{Overview of Analyses}

We again treated students (level-1 units) as nested in schools (level-2 units) and countries (level-3 units). For each study, we regressed each outcome (competitiveness or cooperativeness orientation) on income inequality while excluding or including the same preregistered set of control variables used in Study 1 and while again using MICE with 10 imputed data sets to account for missing values on the control variables. Tables 2 and 3 present the full results and regression equation for the main analysis.

\section{Main Preregistered Analyses}

In Study 2a, consistent with Hypothesis 2A, the higher the income inequality, the higher the domain-specific competitiveness orientation, $\beta=.17[.08, .26], p<.001$, and $\beta_{\mathrm{c}}=.10[.01, .20]$, $p_{\mathrm{c}}=.032$. In Study $2 \mathrm{~b}$, replicating this finding, the higher the income inequality, the higher the domain-general competitiveness orientation, $\beta=.12[.02, .22], p=.015$, and $\beta_{\mathrm{c}}=.16[.01, .31]$, 
Table 3

Studies 1 and 2a-2b: Standardized Coefficients and 95\% CIs of the Multilevel Models Estimating the Effects (Highlighted in Bold) of Income Inequality on Perceived Cooperativeness (Study 1) and Domain-Specific (Study 2a) or Domain-General (Study 2b) Cooperativeness Orientation

\begin{tabular}{|c|c|c|c|c|c|c|}
\hline \multirow{3}{*}{$\begin{array}{l}\text { Measure } \\
\text { Number of students / schools / countries } \\
\text { Without controls }\end{array}$} & \multirow{2}{*}{\multicolumn{2}{|c|}{$\begin{array}{l}\text { Study } 1 \text { (PISA 2018) } \\
475,234 / 20,566 / 75 \\
\end{array}$}} & \multirow{2}{*}{\multicolumn{2}{|c|}{$\begin{array}{c}\text { Study 2a (PISA 2003) } \\
258,469 / 9,907 / 38 \\
\end{array}$}} & \multirow{2}{*}{\multicolumn{2}{|c|}{$\begin{array}{c}\text { Study 2b (PISA 2000) } \\
77,452 \text { / 5,440 / } 32\end{array}$}} \\
\hline & & & & & & \\
\hline & $\beta$ & $95 \% \mathrm{CI}$ & $\beta$ & $95 \% \mathrm{CI}$ & $\beta$ & $95 \% \mathrm{CI}$ \\
\hline Gini coefficient $-G$ & $-.04^{\dagger}$ & {$[-.09, .01]$} & $.12 * * *$ & {$[.05, .2]$} & $.12 *$ & {$[.02, .22]$} \\
\hline Country residual variance $-\operatorname{var}\left(v_{00 \mathrm{k}}\right)$ & .21 & {$[.18, .24]$} & .22 & {$[.18, .28]$} & .28 & {$[.22, .36]$} \\
\hline School-level residual variance $-\operatorname{var}\left(u_{0 \mathrm{jk}}\right)$ & .22 & {$[.22, .23]$} & .16 & {$[.15, .17]$} & .18 & {$[.16, .19]$} \\
\hline Student-level residual variance $-\operatorname{var}\left(e_{\mathrm{ijk}}\right)$ & .98 & {$[.97, .98]$} & .99 & {$[.98, .99]$} & .99 & {$[.98, .99]$} \\
\hline With controls & $\beta$ & $95 \% \mathrm{CI}$ & $\beta$ & $95 \% \mathrm{CI}$ & $\beta$ & $95 \% \mathrm{CI}$ \\
\hline Gini coefficient $-G$ & $-.07 * *$ & {$[-.13,-.02]$} & $.09 *$ & {$[.01, .18]$} & $.19 *$ & {$[.002, .38]$} \\
\hline Age - A & .00 & {$[.00, .00]$} & $-.004 *$ & {$[-.01,-.0,004]$} & $.01 *$ & {$[.009, .02]$} \\
\hline $\operatorname{Sex}(+0.5=$ boys $)-S$ & $.004 *$ & {$[.001, .01]$} & $-.02 * * *$ & {$[-.02,-.01]$} & $-.12 * * *$ & {$[-.13,-.11]$} \\
\hline Origin $(+0.5=$ native $)-O$ & $.01 * * *$ & {$[.004, .01]$} & $-.03 * * *$ & {$[-.03,-.02]$} & $.01 * *$ & {$[.002, .02]$} \\
\hline Social class background $(+0.5=$ high $)-S C$ & $.02 * * *$ & {$[.01, .02]$} & .00 & {$[-.01, .00]$} & $.01^{\dagger}$ & {$[.0003, .01]$} \\
\hline National population $-P P$ & .02 & {$[-.03, .07]$} & -.02 & {$[-.11, .07]$} & .00 & {$[-.11, .11]$} \\
\hline GDP per capita $(\operatorname{logs})-G D P$ & -.01 & {$[-.07, .04]$} & -.04 & {$[-.15, .08]$} & -.06 & {$[-.20, .09]$} \\
\hline Unemployment rate $-U$ & .04 & {$[-.02, .10]$} & .02 & {$[-.09, .13]$} & -.08 & {$[-.27, .11]$} \\
\hline Poverty headcount ratio $-P$ & -.02 & {$[-.07, .03]$} & .01 & {$[-.08, .10]$} & -.01 & {$[-.14, .11]$} \\
\hline Expenditure on education $-E$ & -.03 & {$[-.08, .02]$} & -.03 & {$[-.12, .05]$} & $.13^{*}$ & {$[.02, .25]$} \\
\hline Country residual variance $-\operatorname{var}\left(v_{001}\right.$ & .20 & {$[.17, .24]$} & .27 & {$[.21, .34]$} & .27 & {$[.21, .34]$} \\
\hline School-level residual variance $-\operatorname{var}\left(u_{0 \mathrm{jk}}\right)$ & .22 & {$[.22, .22]$} & .18 & {$[.17, .20]$} & .18 & {$[.17, .20]$} \\
\hline Student-level residual variance $-\operatorname{var}\left(e_{\mathrm{ijk}}\right)$ & .98 & {$[.97, .98]$} & .98 & {$[.97, .98]$} & .98 & {$[.97, .98]$} \\
\hline
\end{tabular}

$p_{\mathrm{c}}=.033$ (for a graphical representation of the findings, see Figure 2). However, in Study 2a, inconsistent with Hypothesis 2B, the higher the income inequality, the higher the domain-specific cooperativeness orientation, $\beta=.12[.05, .20], p<.001$, and $\beta_{\mathrm{c}}=.09$ $[.01, .18], p_{\mathrm{c}}=.024$. In Study $2 \mathrm{~b}$, replicating this surprising finding, the higher the income inequality, the higher the domain-general cooperativeness orientation, $\beta=.12[.02, .23], p=.024$, and $\beta_{\mathrm{c}}=.19[.002, .38], p_{\mathrm{c}}=.048$.

\section{Additional Nonpreregistered Analyses}

When reflecting upon the surprising positive association between income inequality and cooperativeness orientation, we realized that the cooperativeness measures used in PISA contain items that seem to focus on two distinguishable constructs. On the one hand, two items appear to measure an orientation toward instrumental cooperativeness, that is, the benefits (e.g., in terms of achievement) of cooperating ("I do my best work in Mathematics when I work with other students"; "I learn most when I work with other students"). On the other hand, two other items appear to measure an orientation toward intrinsic cooperativeness, that is, the pleasure of cooperating ("In mathematics, I enjoy helping others to work well in a group"; "I like to help other people do well in a group").

In education, it is widely known that academic behaviors and orientations can be located on a continuum, with instrumental (external) reasons at one extreme (e.g., studying because of external contingencies such as grades) and intrinsic reasons at the other extreme (e.g., studying because of an inherent enjoyment in the task; see Ryan \& Deci, 2020). Various academic behaviors and orientations have been found to be undergirded by instrumental or intrinsic reasons: engagement in homework (Adeli et al., 2020), active participation in class (Katz et al., 2011), recreational and academic reading (De Naeghel et al., 2012), the daily pursuit of personal educational goals (Ketonen et al., 2018), and an orientation toward task-mastery and self-improvement (Sommet \& Elliot, 2017). However, the idea that one's orientation toward cooperativeness could also be undergirded by intrinsic or instrumental reasons has yet to be explored.

In economics, it is also widely known that economic agents in the marketplace may sometimes cooperate for instrumental rather than intrinsic reasons, forming strategic alliances with competitors to gain a cooperation-based competitive advantage (Bouncken et al., 2015; for public good experiments distinguishing between altruistic and strategic motives for cooperation, see Burton-Chellew et al., 2017; Yamakawa et al., 2016). In a competitive market, this tactic of cooperating with rivals to create value while also competing against them to capture part of this value is known as coopetition (Köseoğlu et al., 2019). Although the coopetition framework has not previously been used in education research, it is possible that high-inequality contexts foster cooperative behaviors at school driven by strategic concerns to succeed academically (instrumental cooperativeness), rather than by the sole satisfaction that may result from helping others (intrinsic cooperativeness).

From this post hoc reasoning, we derived a revised version of Hypothesis $2 \mathrm{~B}$, namely, Hypothesis $2 \mathrm{~B}^{\prime}$ : Income inequality 
Figure 1

Study 1: Associations Between Income Inequality and Perceived Competitiveness (Left Panel) and Perceived Cooperativeness (Right Panel)
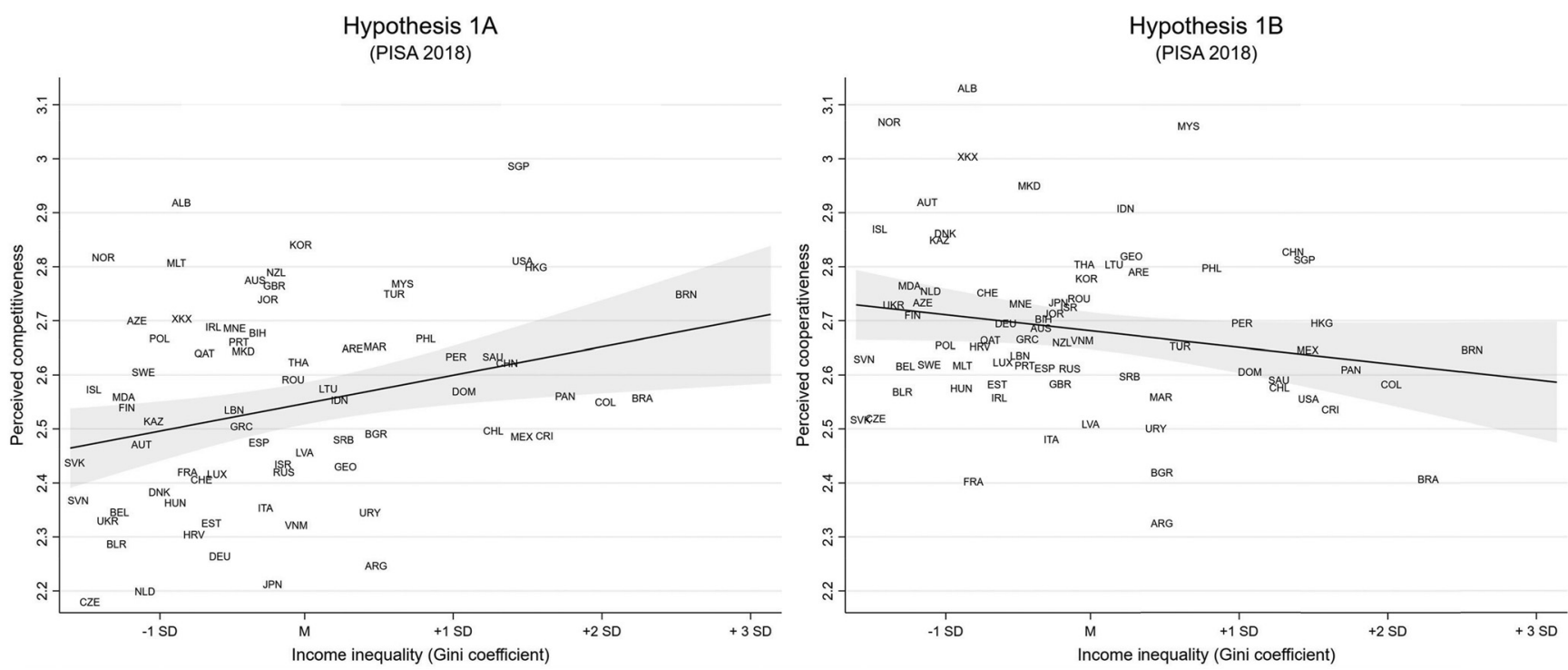

Note. The regression lines were derived from the models without control variables; the estimates from the models with control variables are very similar. The national averages of the outcome variable are indicated by the position of their ISO 3166-1 alpha- 3 codes; gray areas represent $95 \%$ confidence intervals.

is a stronger predictor of instrumental cooperativeness than intrinsic cooperativeness (a between-within interaction hypothesis). To test this new, nonpreregistered prediction, we first conducted confirmatory factor analyses (CFAs) testing whether instrumental and intrinsic cooperativeness items loaded on different factors; second, we conducted multilevel analyses testing the interaction between income inequality and type of cooperativeness.
CFAs Differentiating Instrumental From Intrinsic Cooperativeness. We ran a series of CFAs on the items of the PISA 2003 and 2000 cooperativeness scales. For each country of each study, we compared (a) a model in which the instrumental cooperativeness items were differentiated from the intrinsic cooperativeness items (a two-factor model) with (b) a baseline model in which all items were represented by a single cooperativeness factor (a one-factor model).

\section{Figure 2}

Studies $2 a$ and 2b: Associations Between Income Inequality and Domain-Specific Competitiveness Orientation (Left Panel) and Domain-General Competitiveness Orientation (Right Panel)
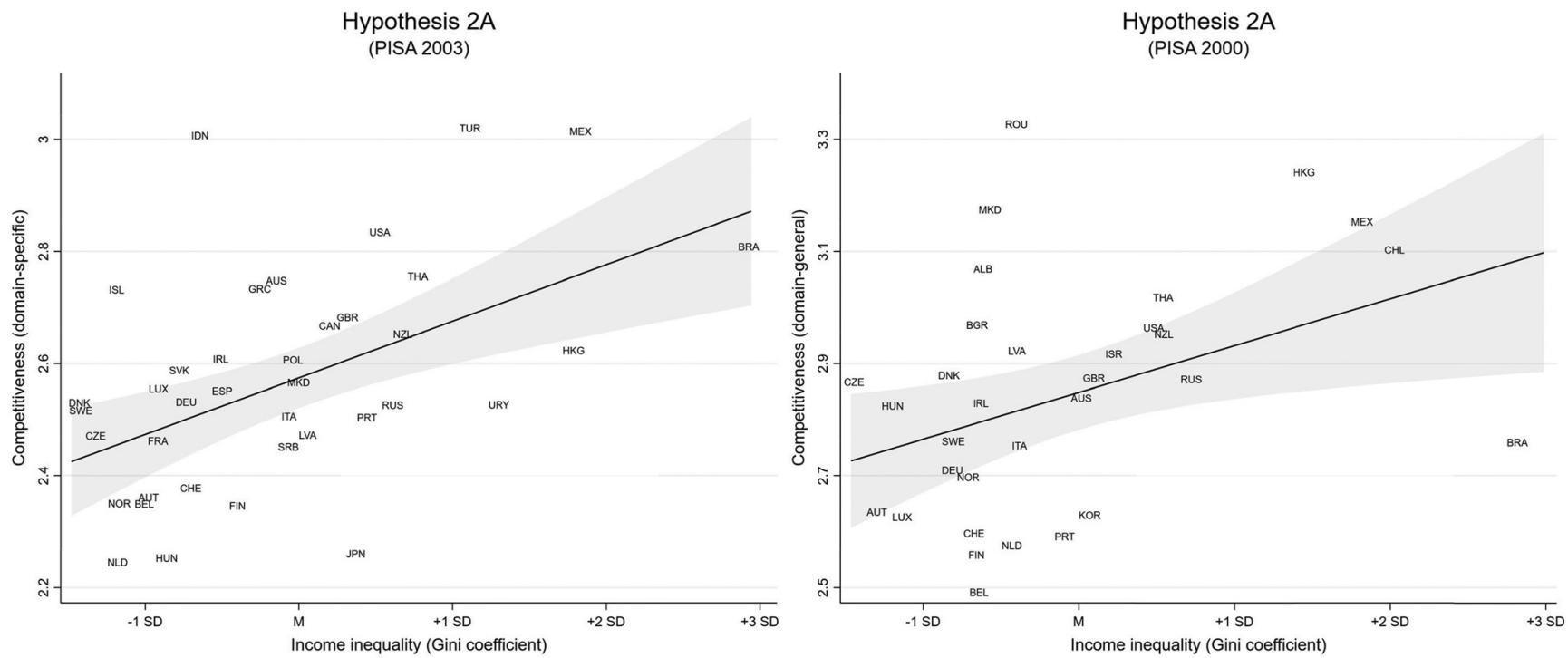

Note. The regression lines were derived from the models without control variables; the estimates from the models with control variables are very similar. The national averages of the outcome variable are indicated by the position of their ISO 3166-1 alpha-3 codes; gray areas represent 95\% confidence intervals. 
The two-factor model was found to fit the data better than the one-factor model in $95 \%$ of the countries of Study 2a and $97 \%$ of the countries of Study $2 b$ (for the country-specific chi-square difference tests, see Table S2). The overall weighted average chi-square difference test was $\chi^{2}=368.13, p<.001$ in Study $2 \mathrm{a}$ and $\chi^{2}=$ $45.31, p<.001$ in Study $2 b$ (for graphical representations with the wordings of all items, see Figure S1). This shows that instrumental and intrinsic cooperativeness are operationally distinct.

Multilevel Models Differentiating the Effect of Income Inequality on Instrumental and Intrinsic Cooperativeness.

Second, we built the same three-level multilevel models used in the main analyses, using the difference between instrumental cooperativeness and intrinsic cooperativeness as the outcome (note that using such a difference score in a regression framework is mathematically equivalent to testing type of cooperativeness as a within-participant variable in an ANOVA framework; for the description of the outcome variables, descriptive statistics, and correlations, see online supplemental materials [p. vii]).

Table S3 presents the full results and the regression equation. In Study $2 \mathrm{a}$, consistent with the new Hypothesis $2 \mathrm{~B}^{\prime}$, the higher the income inequality, the more students favored domain-specific instrumental cooperativeness over domain-specific intrinsic cooperativeness, $\beta=.10[0.06,0.15], p<.001$, and $\beta_{c}=0.12[0.06$, $0.17], p_{\mathrm{c}}<.001$. In Study $2 \mathrm{~b}$, replicating this finding, the higher the income inequality, the more students favored domain-general instrumental cooperativeness over domain-general intrinsic cooperativeness, $\beta=.08[0.05,0.14], p<.001$, and $\beta_{\mathrm{c}}=0.17[0.08$, $0.24], p_{\mathrm{c}}<.001$ (for a graphical representation of the findings, see Figure 3 ). This suggests that students from unequal countries may use cooperation as a strategy to improve their achievement rather than enjoying cooperation for its own sake.

\section{Discussion}

In Studies $2 \mathrm{a}$ and $2 \mathrm{~b}$, we showed that income inequality is associated with a stronger orientation toward both competitiveness (consistent with preregistered Hypothesis 2A) and cooperativeness (inconsistent with preregistered Hypothesis 2B). In follow-up analyses, we then showed that income inequality is associated with a preference toward instrumental rather than intrinsic cooperativeness (consistent with nonpreregistered Hypothesis $2 \mathrm{~B}^{\prime}$ ),

Together with Study 1, Studies $2 \mathrm{a}$ and $2 \mathrm{~b}$ used large-scale crossnational data sets to document robust associations between income inequality and competitiveness/cooperativeness. However, these studies were limited in two important ways: (a) they used observational data that did not enable us to test causality, and (b) the link between income inequality and instrumental/intrinsic cooperativeness was documented in a post hoc analysis. In Study 3, we aimed to replicate the findings from the PISA studies while manipulating income inequality. Specifically, we adapted the "Bimboola paradigm" (Jetten et al., 2015), asking participants to imagine going back to school in a society with either high income inequality or low income inequality. This experimental paradigm has been used by multiple research teams (e.g., Cheng et al., 2021; del Fresno-Díaz et al., 2021; Peters et al., 2021), demonstrating that participants are able to immerse themselves in the context of an unequal or equal society. Furthermore, we focused on young respondents (between 18 and 29), to ensure that participants could easily project themselves into the role of student.

\section{Study 3: The Bimboola Experiment}

In Study 3, we aimed to test the following preregistered hypotheses: "Perceived competitiveness is higher in the high-inequality condition than in the low-inequality condition [Hypothesis 1A],"

Figure 3

Studies $2 a$ and 2b: Associations Between Income Inequality and Domain-Specific (Left Panel) and Domain-General (Right Panel) Instrumental Versus Intrinsic Cooperativeness
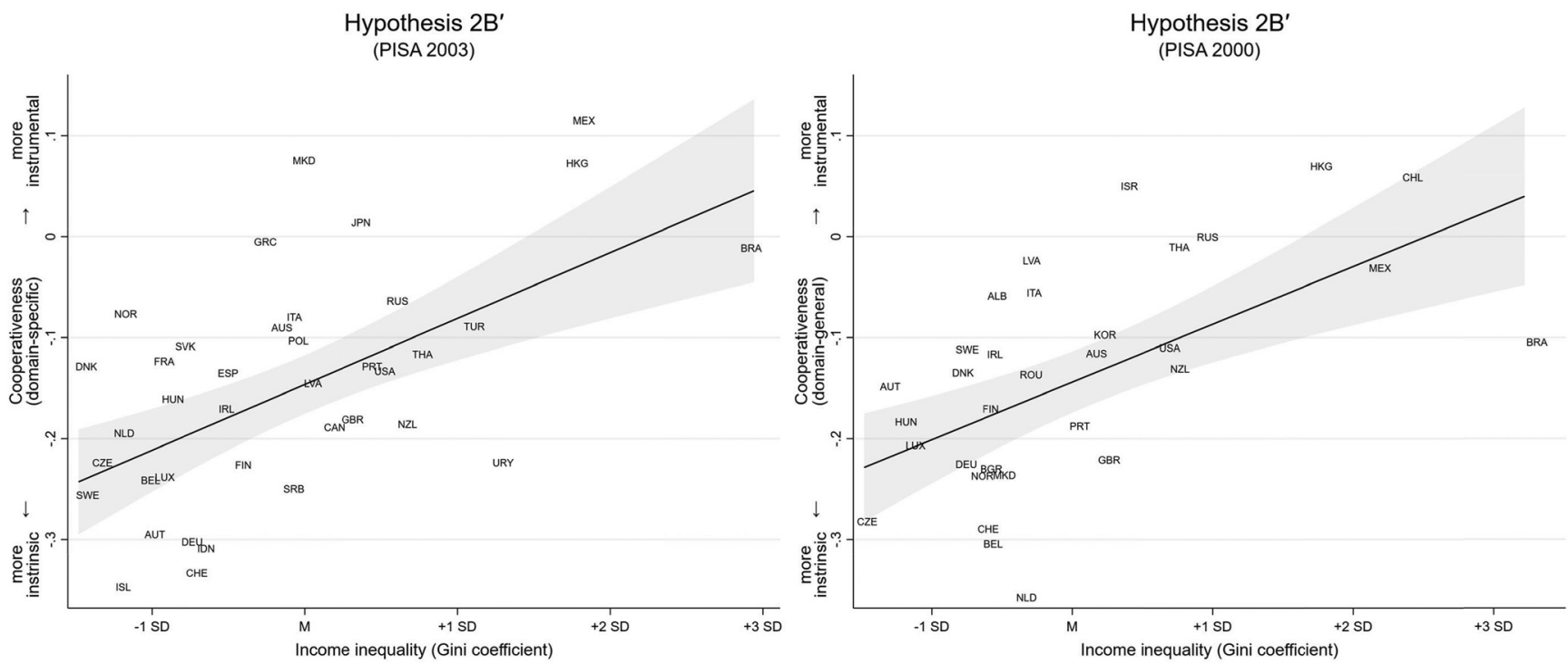

Note. The regression lines were derived from the models without control variables; the estimates from the models with control variables are very similar. The national averages of the outcome variable are indicated by the position of their ISO 3166-1 alpha-3 codes; gray areas represent $95 \%$ confidence intervals. 
"Perceived cooperativeness is lower in the high-inequality condition than in the low-inequality condition [Hypothesis 1B]," "Orientation toward competitiveness is higher in the high-inequality condition than in the low-inequality condition [Hypothesis 2A],"and "Orientation toward instrumental cooperativeness is higher than orientation toward intrinsic cooperativeness in the high-inequality condition; this difference is attenuated in the low-inequality condition [Hypothesis 2B']" (see "Preregistration (The Bimboola Experiment). pdf" on https://osf.io/mz3tn/).

\section{Method}

\section{A Priori Power Analysis}

An a priori preregistered power analysis revealed that 771 participants were needed to detect four small-sized effects of the manipulation of income inequality with a power of .90 (for the power analysis, see online supplemental materials [p. xii]). We oversampled by $10 \%$ and opened our experiment to 850 participants to account for the exclusion of missing data.

\section{Participants}

We used CloudResearch's MTurk Toolkit to recruit participants across the U.S. over the course of several weeks (they received USD 1.00 for participating). We targeted participants 18 to 29 years old to maximize relevance (in the experiment, participants are asked to imagine that they go back to school). As in Studies 1 and 2, we retained all participants with nonmissing values for any of the outcome variables (98.25\% of participants). Moreover, nine participants above 29 years old were incorrectly screened by CloudResearch and were removed from the sample before analyses. The final sample comprised 846 young adults $\left(M_{\text {age }}=24.46 \pm 2.62 ; 42.25 \%\right.$ men; $69.47 \%$ White; $51.60 \%$ 4-year college degree or higher; median equivalized [i.e., household-size adjusted] annual income $=$ USD $33,750)$.

\section{Procedure}

The procedure of the experiment was adapted from the "Bimboola paradigm" (Blake \& Brooks, 2019; Wang et al., 2020). Participants were told that they and their family would become citizens of a fictional society called "Bimboola." They were told that their plan was to go back to school in Bimboola, learn a new skill set, and retrain for a new job. To help participants picture themselves returning to school in this new society, they were given the following open-ended question: "In your own words, please describe the plans for your new life in Bimboola."

\section{Manipulation of Income Inequality}

Participants were randomly assigned to one of two conditions. In the low-inequality condition $(n=420)$, participants were told that the top 20\% in Bimboola earns 60,000 Bimboolean Dollars (BD) per year, the middle $20 \%$ earns $50,000 \mathrm{BD}$, and the bottom $20 \%$ earns 40,000 BD (a 1.5-factor difference between the top and bottom 20\%). In the high-inequality condition $(n=426)$, participants were told that the top 20\% in Bimboola earns 423,000 BD per year, the middle $20 \%$ earns $50,000 \mathrm{BD}$, and the bottom $20 \%$ earns 12,000 BD (a 35-factor difference between the top and bottom $20 \%$ ). In both conditions, participants were assigned to the middle-income group (earning 50,000 BD). Participants were required to report the correct income gap between the top and bottom $20 \%$ to move on to the next page.

Then, participants were told that to begin their new life in Bimboola as a student, they needed to purchase: (a) a house to live in and study, (b) a car to get to and from school, and (c) a holiday to take a break from their courses. For each of these, participants saw pictures of three items that could only be afforded by the top $20 \%$, three items that could also be afforded by the middle $20 \%$, and three items that could also be afforded by the bottom $20 \%$. In the low-inequality condition, the differences between the first and last three items were small (e.g., mid/low- vs. mid/high-priced houses), whereas in the high-inequality condition, the differences were large (e.g., very low- vs. very high-priced houses). In both conditions, the three middle pictures were identical (see the materials in the OSF page of the project). At the end of the task, a manipulation strengthener repeated the key information about income distribution and purchasing power inequality.

\section{Variables}

Following the manipulation, participants were told that they were now in their freshman year at the Bimboolean school. They were told that, as time goes by, they would "learn about the curriculum," "get to know the other students," and "get accustomed to the atmosphere in [their] Bimboolean school." At this point, participants completed our measures. Table S4 presents the correlations between the focal variables.

Perceived Inequality. We adapted Sommet at al.'s (2019) four-item perceived inequality scale (response options ranged from $1=$ Strongly disagree to $7=$ Strongly agree ). We average the items and used this variable as a manipulation check ("In Bimboola, there is a huge gap between rich and poor families"; $\alpha=$ $.98, M=4.80 \pm 2.19$ )

Perceived Competitiveness and Cooperativeness. We used the same measures used in Study 1. Specifically, we adapted the PISA 2018 (originally from Murayama \& Elliot, 2012) four-item measures of perceived competitiveness and cooperativeness (response options ranged from $1=$ Extremely unlikely, $7=$ Extremely likely). We averaged the items to obtain measures of perceived competitiveness (e.g., "Bimboolean students compete with each other"; $\alpha=.93, M=4.86 \pm 1.30)$ and perceived cooperativeness (e.g., "Bimboolean students cooperate with each other"; $\alpha=.95, M=4.87 \pm 1.27$ ).

Competitiveness and Cooperativeness Orientation.

Competitiveness Orientation. We used the same measure used in Studies 2a and 2b. Specifically, we adapted PISA 2000s (originally from Owens \& Barnes, 1992) five-item assessment of domain-general orientation toward competitiveness (response options ranged from 1 = Strongly disagree, $7=$ Strongly agree) . We averaged the items to obtain measures of competitiveness orientation (e.g., "[Now that I am in the first year of Bimboolean school] I try to do better than the other Bimboolean students"; $\alpha=$ $.92, M=5.34 \pm 1.22$ ).

Instrumental Versus Intrinsic Cooperativeness. We adapted Xiong et al.'s (2015) motivation for collaborative learning scale (response options ranged from $1=$ Strongly disagree, $7=$ Strongly agree). Participants were asked about the "possible reasons [they] might like to collaborate with other Bimboolean students." Four 
items measured instrumental cooperativeness (e.g., "Because collaborating with Bimboolean classmates can help me to achieve academic success"; $\alpha=.83, M=4.98 \pm 1.34$ ) and four items measured intrinsic cooperativeness (e.g., "Because collaborating is fun"; $\alpha=.91, M=5.40 \pm 1.06$ ). The two series of items were counterbalanced (instrumental cooperativeness first: $n=420$; intrinsic cooperativeness first: $n=425)$. As indicated in the preregistration, and as in Studies 2a-2b, we used the difference between instrumental cooperativeness and intrinsic cooperativeness to test the between-within interaction Hypothesis $2 \mathrm{~B}^{\prime}(M=.43 \pm 1.13)$.

\section{Results}

\section{Overview of Analyses}

For the manipulation check and each hypothesis, we regressed the outcome on the condition $(-.5=$ low-inequality condition, $+.5=$ high-inequality condition) while excluding or including a preregistered set of five control variables (age, sex, race, education, and equivalized income). For Hypothesis $2 \mathrm{~B}^{\prime}$, we entered the order of presentation of the instrumental and intrinsic cooperativeness variables as an additional control variable. Table 4 presents the full results and the regression equation, and Figure 4 presents a graphical representation of the findings.

\section{Preregistered Analyses}

Manipulation Check. Perceived inequality was higher in the high-inequality condition than in the low-inequality condition, $\beta=$ $.84[.80, .87], p<.001$, and $\beta_{\mathrm{c}}=.85[.81, .88], p_{\mathrm{c}}<.001$. This indicates that the manipulation was effective.

Perceived Competitiveness. Consistent with Hypothesis 1A, and conceptually replicating Study 1, perceived competitiveness was higher in the high-inequality condition than in the low-inequality condition, $\beta=.54[.49, .60], p<.001$, and $\beta_{\mathrm{c}}=.54[.48$, $.60], p_{\mathrm{c}}<.001$.

Perceived Cooperativeness. Consistent with Hypothesis 1B, and conceptually replicating Study 1, perceived cooperativeness was lower in the high-inequality condition than in the low-inequality condition, $\beta=-.50[-.55,-.44], p<.001$, and $\beta_{c}=-.50$ $[-.56,-.44], p_{\mathrm{c}}<.001$.

Competitiveness Orientation. Consistent with Hypothesis $2 \mathrm{~A}$, and conceptually replicating Studies $2 \mathrm{a}$ and $2 \mathrm{~b}$, competitiveness orientation was higher in the high-inequality condition than in the low-inequality condition, $\beta=.24[.17, .31], p<.001$, and $\beta_{\mathrm{c}}=.24[.17, .30], p_{\mathrm{c}}<.001$.

Instrumental Versus Intrinsic Cooperativeness. Consistent with Hypothesis $2 \mathrm{~B}^{\prime}$, and conceptually replicating Studies $2 \mathrm{a}$ and $2 \mathrm{~b}$, instrumental (vs. intrinsic) cooperativeness was favored more in the high-inequality condition than in the low-inequality condition, $\beta=.13[.07, .20], p<.001$, and $\beta=.13[.06, .19], p<.001$. Specifically, instrumental cooperativeness was higher than intrinsic cooperativeness in the high-inequality condition, whereas this difference was attenuated in the low-inequality condition.

\section{Discussion}

In Study 3, we showed that induced income inequality (a) increases perceived competitiveness (consistent with preregistered Hypothesis 1A), (b) decreases perceived cooperativeness (consistent with preregistered Hypothesis 1B), (c) prompts an orientation toward competitiveness (consistent with preregistered Hypothesis 2A), and (d) prompts an orientation toward instrumental rather than intrinsic cooperativeness (consistent with preregistered Hypothesis $2 \mathrm{~B}^{\prime}$ ).

\section{General Discussion}

Income inequality has long been argued to nurture a culture of upward comparison, in which economic agents compete more fiercely against one another for positional goods, lavish lifestyles, and enviable status (Schor, 1998). In this research, we sought to determine whether income inequality fosters an ethos of competitiveness and inhibits cooperativeness among future economic agents, shaping how students experience competitiveness and cooperativeness at school.

\section{Contributions}

\section{Income Inequality, Perceived Competitiveness, and Orientation Toward Competitiveness}

Regarding competitiveness, our observational and experimental evidence show that income inequality is positively associated with both the perception that one's schoolmates are competitive and an orientation toward competitiveness. These findings may be interpreted as follows: When the share of national income received by top earners is larger, the structural incentive to beat the academic competition to reach top-earning positions is higher; that is, income inequality turns school into a breeding ground for competitiveness.

The mechanisms accounting for the association between income inequality and competitiveness might be located at the cultural (e.g., power distance), institutional (e.g., school policies), or interpersonal (e.g., peer influence) level (see Basabe \& Ros, 2005; Marks, 2009; Weiss \& Stuntz, 2004, respectively). However, we believe that parental caregivers and school staff are among the chief agents of socialization who recognize the particular importance of students' future positions in stratified society, and put greater pressure on them to sucessfully navigate the filters of academic selection (for research on income inequality and intensive parenting, see Agostinelli et al., 2020, for research on the role of parental ambition and school principals' values in shaping children's competitiveness, see Berson \& Oreg, 2016; Khadjavi \& Nicklisch, 2018; respectively). In the school context, it is at least plausible that teachers are one of the main facilitators of students' perceiving that school is a competitive arena, and are a driving force emphasizing the importance of competitive values. Indeed, higher levels of national income inequality are associated with higher beliefs in meritocracy (Mijs, 2021), and this kind of belief has been found to influence teachers' practices and students' competitiveness (Autin et al., 2015; Khamzina et al., 2021; Sommet et al., 2017). This echoes the words of Deutsch (1979) when he wrote "schools serve as a socializing influence on children to accept the dominant values within their society" (p. 393). However, our experiment also documents that the mere perception of societal income inequality (without provocation by an external agent) is enough to prompt perceived competitiveness and an 
Table 4

Study 3: Standardized Coefficients and 95\% CIs of the Regression Models Estimating the Effects (Highlighted in Bold) of the Manipulation of Income Inequality on Perceived Competitiveness, Perceived Cooperativeness, Competitiveness Orientation, and Instrumental Versus Intrinsic Cooperativeness

\begin{tabular}{|c|c|c|c|c|c|c|c|c|}
\hline \multirow{2}{*}{$\frac{\text { Measure }}{\text { Number of participants }}$} & \multicolumn{2}{|c|}{ Perceived competitiveness } & \multicolumn{2}{|c|}{ Perceived cooperativeness } & \multicolumn{2}{|c|}{ Competitiveness orientation } & \multicolumn{2}{|c|}{$\begin{array}{c}\text { Instrumental versus } \\
\text { intrinsic cooperativeness }\end{array}$} \\
\hline & 846 & 834 & 846 & 834 & 845 & 834 & 845 & 834 \\
\hline Without controls & $\beta$ & $95 \% \mathrm{CI}$ & $\beta$ & $95 \% \mathrm{CI}$ & $\beta$ & $95 \% \mathrm{CI}$ & $\beta$ & $95 \% \mathrm{CI}$ \\
\hline Income inequality $-I$ & $0.54 * * *$ & {$[0.49,0.60]$} & $-0.50 * * *$ & {$[-0.55,-0.44]$} & $0.24 * * *$ & {$[0.17,0.31]$} & $0.13 * * *$ & {$[0.07,0.20]$} \\
\hline With control variables & $\beta$ & $95 \% \mathrm{CI}$ & $\beta$ & $95 \% \mathrm{CI}$ & $\beta$ & $95 \% \mathrm{CI}$ & $\beta$ & $95 \% \mathrm{CI}$ \\
\hline $\begin{array}{l}\text { Income inequality }-\boldsymbol{I} \\
\text { Age-A } \\
\text { Sex }(+0.5=\text { boys })-S \\
\text { Origin }(+0.5=\text { native })-O \\
\text { Education }(+0.5=\text { high })-E d \\
\text { Equivalized annual income }-E q \\
\text { Order of the scales }-O\end{array}$ & $\begin{array}{l}\mathbf{0 . 5 4} * * * \\
0.04 \\
0.05 \\
-0.02 \\
0.02 \\
-0.05\end{array}$ & $\begin{array}{l}{[\mathbf{0 . 4 8 , 0 . 6 0}]} \\
{[-0.02,0.10]} \\
{[-0.00,0.11]} \\
{[-0.08,0.04]} \\
{[-0.05,0.08]} \\
{[-0.11,0.01]}\end{array}$ & $\begin{array}{c}-\mathbf{0 . 5 0} * * * \\
0.02 \\
0.00 \\
-0.02 \\
0.03 \\
0.03\end{array}$ & $\begin{array}{l}{[-\mathbf{0 . 5 6},-\mathbf{0 . 4 4}]} \\
{[-0.05,0.08]} \\
{[-0.06,0.06]} \\
{[-0.08,0.04]} \\
{[-0.03,0.09]} \\
{[-0.03,0.09]}\end{array}$ & $\begin{array}{l}\mathbf{0 . 2 4} * * * \\
0.03 \\
0.03 \\
-0.10 * * \\
0.04 \\
0.05\end{array}$ & $\begin{array}{l}{[\mathbf{0 . 1 7}, \mathbf{0 . 3 0}]} \\
{[-0.04,0.10]} \\
{[-0.04,0.10]} \\
{[-0.16,-0.03]} \\
{[-0.03,0.11]} \\
{[-0.01,0.12]}\end{array}$ & $\begin{array}{l}\mathbf{0 . 1 3} * * * \\
0.03 \\
0.02 \\
-0.02 \\
0.01 \\
0.02 \\
0.10 * *\end{array}$ & $\begin{array}{l}{[\mathbf{0 . 0 6 , 0 . 1 9}]} \\
{[-0.04,0.10]} \\
{[-0.05,0.08]} \\
{[-0.08,0.05]} \\
{[-0.06,0.09]} \\
{[-0.05,0.09]} \\
{[0.04,0.17]}\end{array}$ \\
\hline
\end{tabular}

Note. The regression equation is $Y_{\mathrm{j}}=B_{0}+B_{1} \times I_{\mathrm{i}}\left[+B_{1} \times A_{\mathrm{i}}+B_{2} \times S_{\mathrm{i}}+B_{3} \times O_{\mathrm{i}}+B_{4} \times E d_{\mathrm{i}}+B_{5} \times E q_{\mathrm{i}}+B_{6} \times O_{\mathrm{i}}\right]+e_{\mathrm{i}}, i=1,2, \ldots, N($ participants); higher-educated participants hold a 4-year college degree; equivalized (household-size adjusted) annual income was computed by dividing household income by the square root of household size (OECD, 2019c); variations in $N \mathrm{~s}$ are due to missing values.

$* * p<.01 . * * * p<.001$.

orientation toward competitiveness (for additional relevant qualitative evidence, see Kim \& Gewirtz, 2019).

\section{Income Inequality, Perceived Cooperativeness, and Orientation Toward Cooperativeness}

Regarding cooperativeness, our results point to a paradox: Income inequality is positively associated with the perception that one's schoolmates are uncooperative (congruent with the above), but it is also positively associated with an orientation toward cooperativeness (seemingly incongruent with the above). Additional evidence resolved this paradox, showing that income inequality is associated with an orientation toward instrumental rather than intrinsic cooperativeness (whereby collaboration is used as a strategic tool to achieve academic success rather than for the inherent enjoyment of the cooperation itself)

Figure 4

Study 3: Effect Income Inequality Manipulation (Low Versus High Inequality) on Perceived Competitiveness (Left Panel), Perceived Cooperativeness (Middle-Left Panel), Competitiveness Orientation (Middle-Right Panel), and Instrumental Versus Intrinsic Cooperativeness (Right Panel)
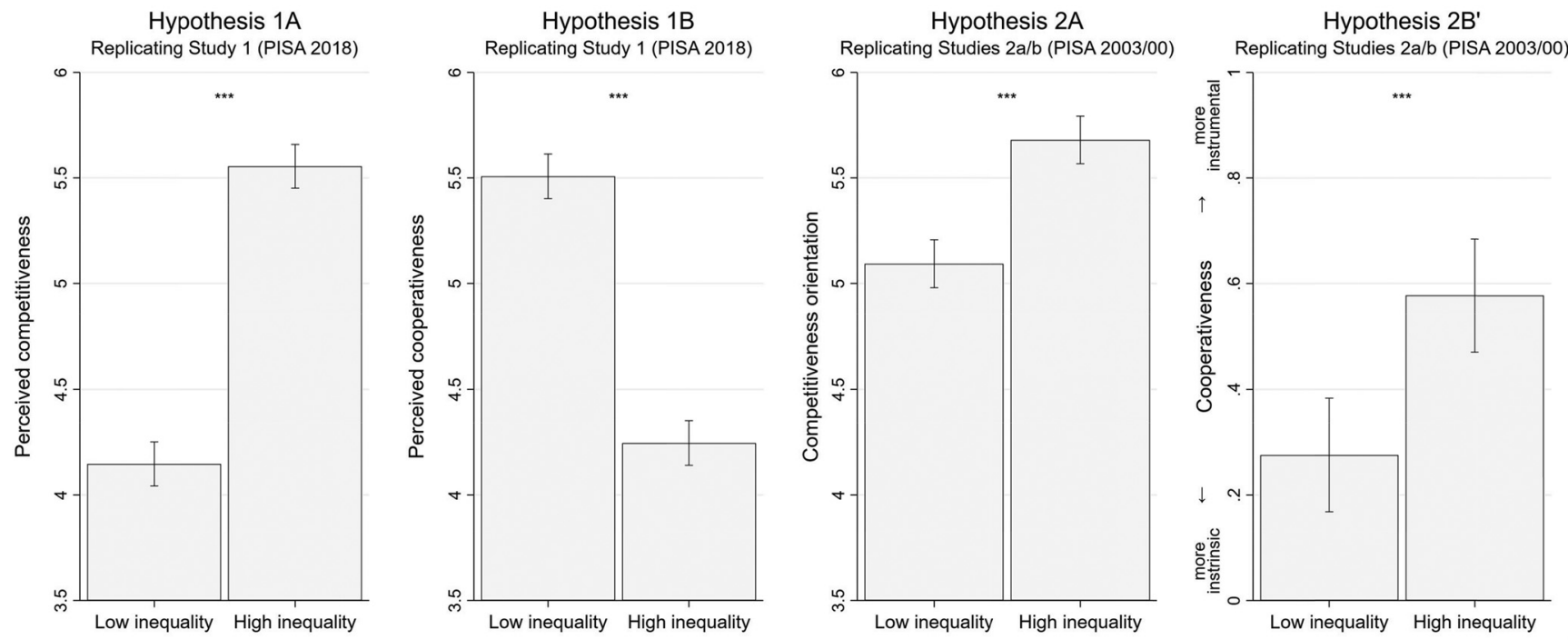

Note. The estimates are from the models without control variables; the estimates from the models with control variables are very similar. Error bars represent $95 \%$ confidence intervals. $* * * p<.001$. 
We believe that these findings can be understood through the lens of the concept of coopetition (Bouncken et al., 2015). In free market economies, firms sometimes forge strategic alliances (e.g., cooperating in activities such as R\&D) while simultaneously competing against one another (e.g., for sales); these coopetitive relationships enable firms to innovate, reduce risk, and share costs to get an edge on their (nonparticipating) competitors. In contexts with high income inequality, students may also come to forge strategic alliances (e.g., cooperating in activities such as homework) while simultaneously competing against each other (e.g., for grades); these coopetitive relationships could enable them to acquire more helpful information, tackle more complex ideas, and learn more to gain an edge in academic selection processes (we believe that the mechanisms accounting for the association between income inequality and coopetitiveness are of the same nature as the mechanisms accounting for the association between income inequality and competitiveness discussed above). These findings are also consistent with a self-determination theory perspective, which differentiates between instrumentally grounded goals (e.g., controlled academic and nonacademic goals) and intrinsically grounded goals (e.g., autonomous academic and nonacademic goals; Acee et al., 2012). However, given that instrumentally grounded goals are associated with lower enthusiasm and commitment (Ryan \& Deci, 2020; Sommet \& Elliot, 2017; Vansteenkiste et al., 2010), it is reasonable to question whether an orientation toward instrumental cooperativeness could result in satisfactory and long-lasting cooperation between students over time.

\section{Limitations}

Three limitations of our research should be acknowledged.

\section{Effect Sizes}

The median estimate from the one-predictor models across our observational studies is $\bar{\beta}=.10$ ( $\beta$ s from one-predictor multilevel models can roughly be interpreted as $r$ s). Although this median effect is small, two considerations should be borne in mind. First, statistically small effects can have societally important consequences when they apply repeatedly to many people (Greenwald et al., 2015). We believe this is the case here: The historical rise in income inequality observed in the last 25 years $(3 / 4$ of the world population live in countries where inequality has grown; United Nations, 2020) may have exerted a continuous impact on the hundreds of millions of students enrolled in secondary school (World Bank, 2020). Second, statistically small effects could also be due to complex indirect mechanisms involved in the effect (Matthay et al., 2021). We believe that this is the case here: As alluded to above, agents of socialization such as teachers might represent one of the pathways through which income inequality affects students' orientations; but not all teachers from unequal societies will encourage students to be more competitive (e.g., due to ideological reluctance or reactance to the general cultural emphasis), thereby weakening the overall effect. As a matter of fact, the median estimate from the one-predictor model in our experiment (that isolated the effect of income inequality at the price of ecological validity) is nearly four times larger $(\bar{\beta}=.37)$ than that observed in our observational studies.

\section{Causality Inferences}

The cross-sectional design used in our observational studies does not allow us to draw causal inferences. In particular, it is possible that societies that are more competitive (or less intrinsically cooperative) tend to move toward greater income inequality, rather than the opposite. While this reverse causality-based account cannot be formally ruled out, we believe it has two weaknesses: (a) it lacks explanatory depth, and (b) it is at odds with available experimental evidence. First, a reverse causality-based account leaves open the question of why there would be cultural differences in the first place (why are some societies more competitive than others? Why are others more intrinsically cooperative?), whereas the idea that income inequality - a macroeconomic predictor-impacts cultural values and norms via school institutions seems to have more explanatory depth. Second, a reverse causality-based account is not consistent with extant experimental evidence documenting that induced income inequality increases competitiveness in the economic environment (e.g., Cheng et al., 2021; Melita et al., 2021; Sommet et al., 2019) and with Study 3, which documents similar effects in the academic environment.

\section{Cultural Variation}

Our observational studies mainly used data from developed countries (though the PISA studies also include LMICs [low- and middle-income countries] such as Kazakhstan, the Philippines, and Morocco), and our experimental study used a U.S. sample. The psychological costs of national income inequality are known to depend on the level of economic development (Ngamaba et al., 2018) and the effects of experimental manipulations may vary (albeit marginally) from one culture to another (Klein et al., 2018). Thus, future research and experimental replication using data from LMICs and/or non-WEIRD (Western educated industrialized rich democracies) countries (Henrich, 2020) are needed to test the generalizability of our findings.

\section{Future Research Directions}

\section{Investigating the Downstream Consequences of Compe- titiveness and Cooperativeness}

In the present research, we did not investigate the downstream consequences of competitiveness and cooperativeness. Traditionally, competitiveness has been perceived as primarily undesirable, whereas cooperativeness has been perceived as primarily desirable (for examples of classical work, see Deutsch, 1949; Kohn, 1992; Mead, 1937). However, studies from the 1990 s demonstrated that competitive contexts could sometimes be neutral or even beneficial for achievement outcomes (e.g., see Epstein \& Harackiewicz, 1992; Stanne et al., 1999; Tauer \& Harackiewicz, 1999). Recent advances in the study of cooperative learning, on the other hand, confirmed that cooperative contexts are overall beneficial for achievement outcomes (Kyndt et al., 2013), although these benefits might be thwarted by competition (for a review, see Butera \& Buchs, 2019). Below, we briefly discuss the state of the art of research on the downstream implications of 
competitiveness and cooperativeness, and formulate future research questions.

Competitiveness. There is evidence in the literature that competitiveness may exert opposing effects on achievement outcomes. Perceiving or being oriented toward competitiveness can be appraised as a threat (e.g., for students low in self-efficacy), and prompts avoidance-based goals (e.g., not falling behind the competition), which may result in negative experiential or achievement-related consequences. Conversely, perceiving or being oriented toward competitiveness can be appraised as a challenge (e.g., for students high in self-efficacy), and prompts approach-based goals (e.g., getting ahead of the competition), which may result in positive experiential or achievement-related consequences (for a review, see Elliot, 2020). Future research questions include: Does income inequality exert opposing effects on educational outcomes via competitiveness (e.g., motivation, performance)? Does income inequality widen the gap between the students who suffer from competition and those who benefit from competition?

Cooperativeness. There is evidence in the literature that cooperativeness exerts beneficial effects on achievement outcomes. Cooperative learning methods have repeatedly been found to be beneficial for interpersonal (e.g., peer relationship) and intrapersonal (e.g., learning) outcomes (Roseth et al., 2008), although the magnitude of the benefits varies from one cultural context to another (Zeneli et al., 2016). To be effective, cooperative learning methods should follow a set of principles, with the first principle being sharing a common goal (Johnson \& Johnson, 2009). As such, cooperative methods tend to lose their benefits when they activate social comparison concerns or negatively interdependent goals (e.g., see Buchs et al., 2021; Roseth et al., 2019). Future research questions include: Does income inequality undermine the positive interpersonal and/or intrapersonal effects of cooperative learning by increasing perceptions of or orientation toward competitiveness? Does income inequality account for the variation in the magnitude of the effect of cooperative learning from one country to another?

\section{Taking the Multifaceted Nature of Competitiveness Into} Account

In the present research, we conceptualized perceived competitiveness and orientation toward competitiveness as omnibus constructs. Over the past decades, scholars have attempted to break down general competitiveness into its subcomponents (for a review, see Fülöp \& Orosz, 2015). In doing so, they distinguished between two main forms of competitiveness: hypercompetitiveness and self-developmental competitiveness (for early work, see Horney, 1937/2013; for contemporary work, see Houston et al., 2002; Newby \& Klein, 2014; Orosz et al., 2018). ${ }^{6}$ On the one hand, hypercompetitiveness is an excessive and hostile form of competitiveness. Hypercompetitive individuals see competition as a zero-sum game where rivals need to be vanquished; they are driven by an indiscriminate desire to win and assert their superiority over others (Ryckman et al., 1990). On the other hand, self-developmental competitiveness is an experiential and epistemic form of competitiveness. Self-developmental competitive individuals see competition as an opportunity for learning and self-discovery; they are driven by the competitive process (enjoying the task and improving) rather than the competitive outcome (defeating others; Ryckman et al., 1996).

Hypercompetitiveness and self-developmental competitiveness are usually seen as destructive and constructive forms of competitiveness, respectively (see Fülöp \& Orosz, 2015). For instance, hypercompetitiveness is associated with a host of antisocial outcomes, such as selfishness, unforgiveness, aggressiveness, procheating attitudes, and deceptive behaviors, whereas self-developmental competitiveness has benign or positive social consequences (Collier et al., 2010; Hibbard \& Buhrmester, 2010; Mudrack et al., 2012; Orosz et al., 2013; Ryckman et al., 1997; Tassi \& Schneider, 1997; Thornton et al., 2009). Moreover, there is evidence that hypercompetitiveness is not predictive (or is poorly predictive) of academic achievement, whereas self-developmental competitiveness is linked with both resilience (i.e., the ability to thrive in the face of adversity) and academic achievement (Bing, 1999; Orosz et al., 2018; Thornton et al., 2011).

It is possible that income inequality predicts either one or both of the above forms of competitiveness. Future research questions include: Does income inequality specifically predict hypercompetitiveness (as it conveys the imperativeness of winning a place at the top of a stratified society)? In that case, could the positive associations between income inequality and academic dishonesty (Neville, 2012; see also Du, Chen, Chi, et al., 2021) or bullying (Elgar et al., 2009) be accounted for by hypercompetitiveness? Alternatively, does income inequality predict both hypercompetitiveness and self-developmental competitiveness? In that case, could the null association between income inequality and the income achievement gap (Chmielewski \& Reardon, 2016) be accounted for by opposing processes via hypercompetitiveness and self-developmental competitiveness?

\section{Conclusion}

Income inequality is a "hot topic" in social science research and policy debates. We believe our work herein offers convincing evidence that income inequality fosters competitiveness at school, showing how macrolevel structural features of the economic system may get into the head of youth and shape microlevel psychological processes such as perceptions and motivations at school.

\section{References}

Acee, T. W., Cho, Y., Kim, J.-I., \& Weinstein, C. E. (2012). Relationships among properties of college students' self-set academic goals and academic achievement. Educational Psychology, 32(6), 681-698. https:// doi.org/10.1080/01443410.2012.712795

\footnotetext{
${ }^{6}$ Scholars have identified a third form of competitiveness: avoidancebased competitiveness. Avoidance-based competitiveness is an egodefensive form of competitiveness grounded in both fear of failure (feeling that one's defeat could cause others to belittle them) and fear of success (feeling that one's victory could cause others to resent them; Ryckman et al., 2009). However, because avoidance-based competitiveness has not been as extensively studied as the other two forms of competitiveness discussed herein, we have chosen to primarily focus the discussion on hypercompetitiveness and self-developmental competitiveness.
} 
Adeli, N., Talepasand, S., \& Nazifi, M. (2020). The role of parents' motivation in students' autonomous motivation for doing homework: Testing a model on basis of self-determination theory. Journal of Applied Psychological Research, 11(1), 151-168.

Agostinelli, F., Doepke, M., Sorrenti, G., \& Zilibotti, F. (2020). It takes a village: The economics of parenting with neighborhood and peer effects. National Bureau of Economic Research. https://doi.org/10.3386/w27050

Alencar, A. I., de Oliveira Siqueira, J., \& Yamamoto, M. E. (2008). Does group size matter? Cheating and cooperation in Brazilian school children. Evolution and Human Behavior, 29(1), 42-48. https://doi.org/10 .1016/j.evolhumbehav.2007.09.001

Alexiou, C., \& Kartiyasa, A. (2020). Does greater income inequality cause increased work hours? New evidence from high income economies. Bulletin of Economic Research, 72(4), 380-392. https://doi.org/10.1111/ boer.12226

Almås, I., Cappelen, A. W., Salvanes, K. G., Sørensen, E. Ø., \& Tungodden, B. (2016). Willingness to compete: Family matters. Management Science, 62(8), 2149-2162. https://doi.org/10.1287/mnsc.2015 .2244

Ames, C., \& Archer, J. (1988). Achievement goals in the classroom: Students' learning strategies and motivation processes. Journal of Educational Psychology, 80(3), 260-267. https://doi.org/10.1037/0022-0663 .80.3.260

Atkinson, A. B. (2003). Income inequality in OECD countries: Data and explanations. CESifo Economic Studies, 49(4), 479-513. https://doi.org/ 10.1093/cesifo/49.4.479

Autin, F., Batruch, A., \& Butera, F. (2015). Social justice in education: How the function of selection in educational institutions predicts support for (non)egalitarian assessment practices. Frontiers in Psychology, 6, 707. https://doi.org/10.3389/fpsyg.2015.00707

Balliet, D., Li, N. P., Macfarlan, S. J., \& Van Vugt, M. (2011). Sex differences in cooperation: A meta-analytic review of social dilemmas. Psychological Bulletin, 137(6), 881-909. https://doi.org/10.1037/a0025354

Bardach, L., Oczlon, S., Pietschnig, J., \& Lüftenegger, M. (2020). Has achievement goal theory been right? A meta-analysis of the relation between goal structures and personal achievement goals. Journal of Educational Psychology, 112(6), 1197-1220. https://doi.org/10.1037/ edu0000419

Bardach, L., Yanagida, T., Morin, A. J., \& Lüftenegger, M. (2021). Is everyone in class in agreement and why (not)? Using student and teacher reports to predict within-class consensus on goal structures. Learning and Instruction, 71, 101400. https://doi.org/10.1016/j.learn instruc.2020.101400

Basabe, N., \& Ros, M. (2005). Cultural dimensions and social behavior correlates: Individualism-Collectivism and Power Distance. Revue Internationale de Psychologie Sociale, 18(1), 189-225.

Batruch, A., Autin, F., \& Butera, F. (2019). The paradoxical role of meritocratic selection in the perpetuation of social inequalities at school. In J. Jetten \& K. Peters (Eds.), The social psychology of inequality (pp. 123-137). Springer. https://doi.org/10.1007/978-3-030-28856-3_8

Batruch, A., Autin, F., Bataillard, F., \& Butera, F. (2019). School selection and the social class divide: How tracking contributes to the reproduction of inequalities. Personality and Social Psychology Bulletin, 45(3), 477-490. https://doi.org/10.1177/0146167218791804

Bauer, M., Chytilová, J., \& Pertold-Gebicka, B. (2014). Parental background and other-regarding preferences in children. Experimental Economics, 17(1), 24-46. https://doi.org/10.1007/s10683-013-9355-y

Berson, Y., \& Oreg, S. (2016). The role of school principals in shaping children's values. Psychological Science, 27(12), 1539-1549. https://doi .org/10.1177/0956797616670147

Bing, M. N. (1999). Hypercompetitiveness in academia: Achieving criterion-related validity from item context specificity. Journal of Personality Assessment, 73(1), 80-99. https://doi.org/10.1207/S15327752JPA730106
Blake, K. R., \& Brooks, R. C. (2019). Status anxiety mediates the positive relationship between income inequality and sexualization. Proceedings of the National Academy of Sciences of the United States of America, 116(50), 25029-25033. https://doi.org/10.1073/pnas.1909806116

Bleidorn, W. (2015). What accounts for personality maturation in early adulthood? Current Directions in Psychological Science, 24(3), 245-252. https://doi.org/10.1177/0963721414568662

Borghuis, J., Denissen, J. J. A., Oberski, D., Sijtsma, K., Meeus, W. H. J., Branje, S., Koot, H. M., \& Bleidorn, W. (2017). Big Five personality stability, change, and codevelopment across adolescence and early adulthood. Journal of Personality and Social Psychology, 113(4), 641-657. https://doi.org/10.1037/pspp0000138

Bouncken, R. B., Gast, J., Kraus, S., \& Bogers, M. (2015). Coopetition: A systematic review, synthesis, and future research directions. Review of Managerial Science, 9(3), 577-601. https://doi.org/10.1007/s11846-015 $-0168-6$

Bowles, S., \& Park, Y. (2005). Emulation, inequality, and work hours: Was Thorsten Veblen right? Economic Journal, 115(507), F397-F412. https://doi.org/10.1111/j.1468-0297.2005.01042.x

Brown, S. P., Cron, W. L., \& Slocum, J. W., Jr. (1998). Effects of trait competitiveness and perceived intraorganizational competition on salesperson goal setting and performance. Journal of Marketing, 62(4), 88-98. https://doi.org/10.1177/002224299806200407

Buchs, C., Dumesnil, A., Chanal, J., \& Butera, F. (2021). Dual effects of partner's competence: Resource interdependence in cooperative learning at elementary school. Education Sciences, 11(5), 210. https://doi.org/10 .3390/educsci11050210

Burton-Chellew, M. N., El Mouden, C., \& West, S. A. (2017). Evidence for strategic cooperation in humans. Proceedings: Biological Sciences, 284(1856), 20170689. https://doi.org/10.1098/rspb.2017.0689

Butera, F., \& Buchs, C. (2019). Social interdependence and the promotion of cooperative learning. In Social psychology in action (pp. 111-127). Springer. https://doi.org/10.1007/978-3-030-13788-5_8

Butera, F., Świątkowski, W., \& Dompnier, B. (2021). Competition in education. In S. Garcia, A. Tor, \& A. J. Elliot (Eds.), The Oxford handbook on the psychology of competition. Oxford University Press.

Buttrick, N. R., \& Oishi, S. (2017). The psychological consequences of income inequality. Social and Personality Psychology Compass, 11(3), e12304. https://doi.org/10.1111/spc3.12304

Cesarini, D., Dawes, C. T., Fowler, J. H., Johannesson, M., Lichtenstein, P., \& Wallace, B. (2008). Heritability of cooperative behavior in the trust game. Proceedings of the National Academy of Sciences of the United States of America, 105(10), 3721-3726. https://doi.org/10.1073/ pnas.0710069105

Cheng, L., Hao, M., \& Wang, F. (2021). Beware of the 'bad guys': Economic inequality, perceived competition, and social vigilance. Revue Internationale de Psychologie Sociale, 34(1), 9. https://doi.org/10.5334/ irsp.497

Chmielewski, A. K. (2014). An international comparison of achievement inequality in within-and between-school tracking systems. American Journal of Education, 120(3), 293-324. https://doi.org/10.1086/675529

Chmielewski, A. K., \& Reardon, S. F. (2016). Patterns of cross-national variation in the association between income and academic achievement AERA Open, 2(3), 233285841664959. https://doi.org/10.1177/23328 58416649593

Christen, M., \& Morgan, R. M. (2005). Keeping up with the Joneses: Analyzing the effect of income inequality on consumer borrowing. Quantitative Marketing and Economics, 3(2), 145-173. https://doi.org/10 .1007/s11129-005-0351-1

Cloninger, C. R., Svrakic, D. M., \& Przybeck, T. R. (1993). A psychobiological model of temperament and character. Archives of General Psychiatry, 50(12), 975-990. https://doi.org/10.1001/archpsyc.1993.01820240059008

Collier, S. A., Ryckman, R. M., Thornton, B., \& Gold, J. A. (2010). Competitive personality attitudes and forgiveness of others. The Journal of 
Psychology, 144(6), 535-543. https://doi.org/10.1080/00223980.2010 .511305

Connelly, C. E., Ford, D. P., Turel, O., Gallupe, B., \& Zweig, D. (2014). 'I'm busy (and competitive)!'Antecedents of knowledge sharing under pressure. Knowledge Management Research and Practice, 12(1), 74-85. https://doi.org/10.1057/kmrp.2012.61

Côté, S., House, J., \& Willer, R. (2015). High economic inequality leads higher-income individuals to be less generous. Proceedings of the National Academy of Sciences of the United States of America, 112(52), 15838-15843. https://doi.org/10.1073/pnas.1511536112

Darnon, C., Dompnier, B., Delmas, F., Pulfrey, C., \& Butera, F. (2009). Achievement goal promotion at university: Social desirability and social utility of mastery and performance goals. Journal of Personality and Social Psychology, 96(1), 119-134. https://doi.org/10.1037/a0012824

De Naeghel, J., Van Keer, H., Vansteenkiste, M., \& Rosseel, Y. (2012). The relation between elementary students' recreational and academic reading motivation, reading frequency, engagement, and comprehension: A self-determination theory perspective. Journal of Educational Psychology, 104(4), 1006-1021. https://doi.org/10.1037/a0027800

de Vries, R., Gosling, S., \& Potter, J. (2011). Income inequality and personality: Are less equal U.S. states less agreeable? Social Science \& Medicine, 72(12), 1978-1985. https://doi.org/10.1016/j.socscimed.2011 .03 .046

del Fresno-Díaz, Á., Sánchez-Rodríguez, Á., \& Willis, G. B. (2021). I choose to be powerful: Economic inequality encourages preferences of power over status positions. The Social Science Journal. Advance online publication. https://doi.org/10.1080/03623319.2021.1949547

Deutsch, M. (1949). A theory of co-operation and competition. Human Relations, 2(2), 129-152. https://doi.org/10.1177/001872674900200204

Deutsch, M. (1979). Education and distributive justice: Some reflections on grading systems. American Psychologist, 34(5), 391-401. https://doi .org/10.1037/0003-066X.34.5.391

Dik, G., \& Aarts, H. (2007). Behavioral cues to others' motivation and goal pursuits: The perception of effort facilitates goal inference and contagion. Journal of Experimental Social Psychology, 43(5), 727-737. https://doi.org/10.1016/j.jesp.2006.09.002

Doepke, M., \& Zilibotti, F. (2019). Love, money, and parenting: How economics explains the way we raise our kids. Princeton University Press.

Domina, T., Penner, A., \& Penner, E. (2017). Categorical inequality: Schools as sorting machines. Annual Review of Sociology, 43, 311-330. https://doi.org/10.1146/annurev-soc-060116-053354

Dornbusch, S. M., Glasgow, K. L., \& Lin, I. C. (1996). The social structure of schooling. Annual Review of Psychology, 47(1), 401-429. https://doi .org/10.1146/annurev.psych.47.1.401

Du, H., Chen, A., Chi, P., \& King, R. B. (2021). Income inequality reduces civic honesty. Social Psychological \& Personality Science, 12(4), 537-543. https://doi.org/10.1177/1948550620929495

Du, H., Chen, A., Li, Y., Ma, L., Xing, Q., \& Nie, Y. (2021). Perceived income inequality increases status seeking among low social class individuals. Asian Journal of Social Psychology. Advance online publication. https://doi.org/10.1111/ajsp.12455

Durante, F., Fiske, S. T., Kervyn, N., Cuddy, A. J. C., Akande, A. D., Adetoun, B. E., Adewuyi, M. F., Tserere, M. M., Ramiah, A. A., Mastor, K. A., Barlow, F. K., Bonn, G., Tafarodi, R. W., Bosak, J., Cairns, E., Doherty, C., Capozza, D., Chandran, A., Chryssochoou, X., . . . Storari, C. C. (2013). Nations' income inequality predicts ambivalence in stereotype content: How societies mind the gap. British Journal of Social Psychology, 52(4), 726-746. https://doi.org/10.1111/bjso .12005

Elgar, F. J., Craig, W., Boyce, W., Morgan, A., \& Vella-Zarb, R. (2009). Income inequality and school bullying: Multilevel study of adolescents in 37 countries. The Journal of Adolescent Health, 45(4), 351-359. https://doi.org/10.1016/j.jadohealth.2009.04.004
Elliot, A. J. (2020). Competition and achievement outcomes: A hierarchical motivational analysis. Motivation Science, 6(1), 3-11. https://doi .org/10.1037/mot0000164

Elliot, A. J., Jury, M., \& Murayama, K. (2018). Trait and perceived environmental competitiveness in achievement situations. Journal of Personality, 86(3), 353-367. https://doi.org/10.1111/jopy.12320

Epstein, J. A., \& Harackiewicz, J. M. (1992). Winning is not enough: The effects of competition and achievement orientation on intrinsic interest. Personality and Social Psychology Bulletin, 18(2), 128-138. https://doi .org/10.1177/0146167292182003

Fligstein, N., Hastings, O. P., \& Goldstein, A. (2017). Keeping up with the Joneses: How households fared in the era of high income inequality and the housing price bubble, 1999-2007. Socius: Sociological Research for a Dynamic World, 3, 237802311772233-237802311772215. https://doi .org/10.1177/2378023117722330

Fülöp, M., \& Orosz, G. (2015). State of the art in competition research. In R. A. Scott, M. C. Buchmann, \& S. M. Kosslyn (Eds.), Emerging trends in the social and behavioral sciences: An interdisciplinary, searchable, and linkable resource (pp. 1-16). Wiley and Sons. https://doi.org/10 .1002/9781118900772.etrds0317

Garcia, S. M., Tor, A., \& Schiff, T. M. (2013). The psychology of competition: A social comparison perspective. Perspectives on Psychological Science, 8(6), 634-650. https://doi.org/10.1177/1745691613504114

Greenwald, A. G., Banaji, M. R., \& Nosek, B. A. (2015). Statistically small effects of the implicit association test can have societally large effects. Journal of Personality and Social Psychology, 108(4), 553-561. https://doi.org/10.1037/pspa0000016

Henrich, J. (2020). The weirdest people in the world: How the West became psychologically peculiar and particularly prosperous. Farrar, Straus \& Giroux.

Hibbard, D. R., \& Buhrmester, D. (2010). Competitiveness, gender, and adjustment among adolescents. Sex Roles, 63(5-6), 412-424. https://doi .org/10.1007/s11199-010-9809-z

Horney, K. (2013). The neurotic personality of our time. Routledge. (Original work published 1937) https://doi.org/10.4324/9781315010533

Houston, J. M., Mcintire, S. A., Kinnie, J., \& Terry, C. (2002). A factorial analysis of scales measuring competitiveness. Educational and Psychological Measurement, 62(2), 284-298.

Jetten, J., Mols, F., \& Postmes, T. (2015). Relative deprivation and relative wealth enhances anti-immigrant sentiments: The v-curve re-examined. PLoS ONE, 10(10), e0139156. https://doi.org/10.1371/journal.pone .0139156

Johnson, D. W., \& Johnson, R. T. (1974). Instructional goal structure: Cooperative, competitive, or individualistic. Review of Educational Research, 44(2), 213-240. https://doi.org/10.3102/00346543044002213

Johnson, D. W., \& Johnson, R. T. (2009). An educational psychology success story: Social interdependence theory and cooperative learning. Educational Researcher, 38(5), 365-379. https://doi.org/10.3102/001318 9X09339057

Johnson, D. W., \& Johnson, R. T. (2021). Learning Together and Alone: The History of Our Involvement in Cooperative Learning. In $\mathrm{N}$. Davidson (Ed.), Pioneering perspectives in cooperative learning (pp. 44-62). Routledge.

Karabenick, S. A. (1994). Relation of perceived teacher support of student questioning to students' beliefs about teacher attributions for questioning and perceived classroom learning environment. Learning and Individual Differences, 6(2), 187-204. https://doi.org/10.1016/1041-6080(94)90009-4

Katz, I., Kaplan, A., \& Buzukashvily, T. (2011). The role of parents' motivation in students' autonomous motivation for doing homework. Learning and Individual Differences, 21(4), 376-386. https://doi.org/10.1016/ j.lindif.2011.04.001

Kawachi, I., \& Kennedy, B. P. (1999). Income inequality and health: Pathways and mechanisms. Health Services Research, 34(1 Pt. 2), 215-227. 
Ketonen, E. E., Dietrich, J., Moeller, J., Salmela-Aro, K., \& Lonka, K. (2018). The role of daily autonomous and controlled educational goals in students' academic emotion states: An experience sampling method approach. Learning and Instruction, 53, 10-20. https://doi.org/10.1016/j .learninstruc.2017.07.003

Khadjavi, M., \& Nicklisch, A. (2018). Parents' ambitions and children's competitiveness. Journal of Economic Psychology, 67, 87-102. https:// doi.org/10.1016/j.joep.2018.05.004

Khamzina, K., Jury, M., Ducreux, E., \& Desombre, C. (2021). The conflict between inclusive education and the selection function of schools in the minds of French teachers. Teaching and Teacher Education, 106, 103454. https://doi.org/10.1016/j.tate.2021.103454

Kim, C.-Y., Gewirtz, S. (2019). 'It's Not Something I Can Change . . .': Children's perceptions of inequality and their agency in relation to their occupational choices. Child Indicators Research, 12(6), 2013-2034. https://doi.org/10.1007/s12187-019-9624-1

Kim, Y., Sommet, N., Na, J., \& Spini, D. (2021). Social class—not income inequality-predicts social and institutional trust. Social Psychological \& Personality Science. Advance online publication. https://doi.org/10 $.1177 / 1948550621999272$

King, R. B., \& Mendoza, N. B. (2020). Achievement goal contagion: Mastery and performance goals spread among classmates. Social Psychology of Education, 23(3), 795-814. https://doi.org/10.1007/s11218-020 -09559-x

Klein, R. A., Vianello, M., Hasselman, F., Adams, B. G., Adams, R. B., Alper, S., Aveyard, M., Axt, J. R., Babalola, M. T., Bahník, Š., Batra, R., Berkics, M., Bernstein, M. J., Berry, D. R., Bialobrzeska, O., Binan, E. D., Bocian, K., Brandt, M. J., Busching, R., . . Nosek, B. A. (2018). Many Labs 2: Investigating variation in replicability across samples and settings. Advances in Methods and Practices in Psychological Science, 1(4), 443-490. https://doi.org/10.1177/2515245918810225

Kohn, A. (1992). No contest: The case against competition. Houghton Mifflin Harcourt.

Köseoğlu, M. A., Yildiz, M., Okumus, F., \& Barca, M. (2019). The intellectual structure of coopetition: Past, present and future. Journal of Strategy and Management, 12(1), 2-29. https://doi.org/10.1108/JSMA -07-2018-0073

Krueger, J. I., DiDonato, T. E., \& Freestone, D. (2012). Social projection can solve social dilemmas. Psychological Inquiry, 23(1), 1-27. https:// doi.org/10.1080/1047840X.2012.641167

Kyndt, E., Raes, E., Lismont, B., Timmers, F., Cascallar, E., \& Dochy, F. (2013). A meta-analysis of the effects of face-to-face cooperative learning. Do recent studies falsify or verify earlier findings? Educational Research Review, 10, 133-149. https://doi.org/10.1016/j.edurev.2013.02.002

Lerdpornkulrat, T., Koul, R., \& Poondej, C. (2018). Relationship between perceptions of classroom climate and institutional goal structures and student motivation, engagement and intention to persist in college. Journal of Further and Higher Education, 42(1), 102-115. https://doi.org/10 .1080/0309877X.2016.1206855

Marks, G. (2009). Accounting for school-sector differences in university entrance performance. Australian Journal of Education, 53(1), 19-38. https://doi.org/10.1177/000494410905300103

Matthay, E. C., Hagan, E., Gottlieb, L. M., Tan, M. L., Vlahov, D., Adler, N., \& Glymour, M. M. (2021). Powering population health research: Considerations for plausible and actionable effect sizes. SSM - Population Health, 14, 100789. https://doi.org/10.1016/j.ssmph.2021.100789

Mead, M. (1937). Cooperation and competition among primitive peoples. McGraw-Hill. https://doi.org/10.1037/13891-000

Meece, J. L., Anderman, E. M., \& Anderman, L. H. (2006). Classroom goal structure, student motivation, and academic achievement. Аnпиаl Review of Psychology, 57, 487-503. https://doi.org/10.1146/annurev .psych.56.091103.070258
Melita, D., Willis, G. B., \& Rodríguez-Bailón, R. (2021). Economic inequality increases status anxiety through perceived contextual competitiveness. Frontiers in Psychology, 12, 637365. https://doi.org/10.3389/fpsyg.2021.637365

Meyer, L. H., McClure, J., Walkey, F., Weir, K. F., \& McKenzie, L. (2009). Secondary student motivation orientations and standards-based achievement outcomes. The British Journal of Educational Psychology, 79(Pt. 2), 273-293. https://doi.org/10.1348/000709908X354591

Mijs, J. J. (2021). The paradox of inequality: Income inequality and belief in meritocracy go hand in hand. Socio-Economic Review, 19(1), 7-35. https://doi.org/10.1093/ser/mwy051

Mishra, S., Hing, L. S. S., \& Lalumiere, M. L. (2015). Inequality and risk-taking. Evolutionary Psychology, 13(3), 147470491559629-147470491559611. https://doi.org/10.1177/1474704915596295

Mudrack, P. E., Bloodgood, J. M., \& Turnley, W. H. (2012). Some ethical implications of individual competitiveness. Journal of Business Ethics, 108(3), 347-359. https://doi.org/10.1007/s10551-011-1094-4

Murayama, K., \& Elliot, A. J. (2012). The competition-performance relation: A meta-analytic review and test of the opposing processes model of competition and performance. Psychological Bulletin, 138(6), 1035-1070. https://doi.org/10.1037/a0028324

Neville, L. (2012). Do economic equality and generalized trust inhibit academic dishonesty? Evidence from state-level search-engine queries. Psychological Science, 23(4), 339-345. https://doi.org/10.1177/09567 97611435980

Newby, J. L., \& Klein, R. G. (2014). Competitiveness reconceptualized: Psychometric development of the competitiveness orientation measure as a unified measure of trait competitiveness. The Psychological Record, 64(4), 879-895.

Ngamaba, K. H., Panagioti, M., \& Armitage, C. J. (2018). Income inequality and subjective well-being: A systematic review and meta-analysis. Quality of Life Research, 27(3), 577-596. https://doi.org/10.1007/ s11136-017-1719-x

Nishi, A., Shirado, H., Rand, D. G., \& Christakis, N. A. (2015). Inequality and visibility of wealth in experimental social networks. Nature, 526(7573), 426-429. https://doi.org/10.1038/nature15392

OECD. (2003). Literacy skills for the world of tomorrow: Further results from PISA 2000. OECD Publishing.

OECD. (2004). Learning for tomorrow's world: First results from PISA 2003. OECD Publishing.

OECD. (2019a). Education at a glance 2019: OECD indicators. OECD Publishing.

OECD. (2019b). PISA 2018 results (Volume III): What school life means for students' lives. OECD Publishing.

OECD. (2019c). Society at a glance 2019: OECD social indicators. OECD Publishing.

OECD. (2019d). Under pressure: The squeezed middle class. OECD Publishing.

Olson, J. M., Vernon, P. A., Harris, J. A., \& Jang, K. L. (2001). The heritability of attitudes: A study of twins. Journal of Personality and Social Psychology, 80(6), 845-860. https://doi.org/10.1037/0022-3514.80.6.845

Orosz, G., Farkas, D., \& Roland-Lévy, C. (2013). Are competition and extrinsic motivation reliable predictors of academic cheating? Frontiers in Psychology, 4, 87. https://doi.org/10.3389/fpsyg.2013.00087

Orosz, G., Tóth-Király, I., Büki, N., Ivaskevics, K., Bőthe, B., \& Fülöp, M. (2018). The four faces of competition: The development of the Multidimensional Competitive Orientation Inventory. Frontiers in Psychology, 9, 779https://doi.org/10.3389/fpsyg.2018.00779

Owens, L., \& Barnes, J. (1982). The relationships between cooperative, competitive, and individualized learning preferences and students' perceptions of classroom learning atmosphere. American Educational Research Journal, 19(2), 182-200. https://doi.org/10.3102/00028312019002182

Owens, L., \& Barnes, J. (1992). Learning preferences scales. ACER.

Paskow, M., Gërxhani, K., \& van der Werfhorst, H. (2013). Income inequality and status anxiety (GINI Discussion Paper 90). AIAS. 
Payne, B. K., Brown-Iannuzzi, J. L., \& Hannay, J. W. (2017). Economic inequality increases risk taking. Proceedings of the National Academy of Sciences of the United States of America, 114(18), 4643-4648. https:// doi.org/10.1073/pnas.1616453114

Peters, K., Jetten, J., Tanjitpiyanond, P., Wang, Z., Mols, F., \& Verkuyten, M. (2021). The language of inequality: Evidence economic inequality increases wealth category salience. Personality and Social Psychology Bulletin. Advance online publication. https://doi.org/10.1177/01461672211036627

Präg, P., Mills, M., \& Wittek, R. (2014). Income and income inequality as social determinants of health: Do social comparisons play a role? European Sociological Review, 30(2), 218-229. https://doi.org/10.1093/esr/ jct035

Pulfrey, C., Buchs, C., \& Butera, F. (2011). Why grades engender performance-avoidance goals: The mediating role of autonomous motivation. Journal of Educational Psychology, 103(3), 683-700. https://doi.org/10 1037/a0023911

Rodríguez-Bailón, R., Sánchez-Rodríguez, Á., García-Sánchez, E., Petkanopoulou, K., \& Willis, G. B. (2020). Inequality is in the air: Contextual psychosocial effects of power and social class. Current Opinion in Psychology, 33, 120-125. https://doi.org/10.1016/j.copsyc.2019.07.004

Rosenbaum, S. M., Billinger, S., Twerefou, D. K., \& Isola, W. A. (2016). Income inequality and cooperative propensities in developing economies: Summarizing the preliminary experimental evidence. International Journal of Social Economics, 43(12), 1460-1480. https://doi.org/ 10.1108/IJSE-04-2015-0109

Roseth, C. J., Johnson, D. W., \& Johnson, R. T. (2008). Promoting early adolescents' achievement and peer relationships: The effects of cooperative, competitive, and individualistic goal structures. Psychological Bulletin, 134(2), 223-246. https://doi.org/10.1037/0033-2909.134.2.223

Roseth, C. J., Lee, Y., \& Saltarelli, W. A. (2019). Reconsidering jigsaw social psychology: Longitudinal effects on social interdependence, sociocognitive conflict regulation, motivation, and achievement. Journal of Educational Psychology, 111(1), 149-169. https://doi.org/10.1037/ edu0000257

Ryan, R. M., \& Deci, E. L. (2020). Intrinsic and extrinsic motivation from a self-determination theory perspective: Definitions, theory, practices, and future directions. Contemporary Educational Psychology, 61, 101860. https://doi.org/10.1016/j.cedpsych.2020.101860

Ryckman, R. M., Hammer, M., Kaczor, L. M., \& Gold, J. A. (1990). Construction of a hypercompetitive attitude scale. Journal of Personality Assessment, 55(3-4), 630-639.

Ryckman, R. M., Hammer, M., Kaczor, L. M., \& Gold, J. A. (1996). Construction of a personal development competitive attitude scale. Journal of Personality Assessment, 66(2), 374-385. https://doi.org/10.1207/ s15327752jpa6602_15

Ryckman, R. M., Libby, C. R., van den Borne, B., Gold, J. A., \& Lindner, M. A. (1997). Values of hypercompetitive and personal development competitive individuals. Journal of Personality Assessment, 69(2), 271-283. https://doi.org/10.1207/s15327752jpa6902_2

Ryckman, R. M., Thornton, B., \& Gold, J. A. (2009). Assessing competition avoidance as a basic personality dimension. The Journal of Psychology, 143(2), 175-192. https://doi.org/10.3200/JRLP.143.2.175-192

Sánchez-Rodríguez, Á., Rodríguez-Bailón, R., \& Willis, G. B. (2020). Economic inequality affects perceived normative values. Group Processes \& Intergroup Relations. Advance online publication. https://doi .org/10.1177/1368430220968141

Sánchez-Rodríguez, Á., Willis, G. B., Jetten, J., \& Rodríguez-Bailón, R. (2019). Economic inequality enhances inferences that the normative climate is individualistic and competitive. European Journal of Social Psychology, 49(6), 1114-1127. https://doi.org/10.1002/ejsp.2557

Schmukle, S. C., Korndörfer, M., \& Egloff, B. (2019). No evidence that economic inequality moderates the effect of income on generosity. Proceedings of the National Academy of Sciences of the United States of America, 116(20), 9790-9795. https://doi.org/10.1073/pnas.1807942116
Schneider, B. H., Benenson, J., Fülöp, M., Berkics, M., \& Sándor, M. (2011). Cooperation and competition. In P. K. Smith \& C. H. Hart (Eds.), The Wiley-Blackwell handbook of childhood social development (2nd ed.). Wiley. https://doi.org/10.1002/9781444390933.ch25

Schneider, S. M. (2019). Why income inequality is dissatisfying-Perceptions of social status and the inequality-satisfaction link in Europe. European Sociological Review, 35(3), 409-430. https://doi.org/10.1093/ esr/jcz003

Schor, J. B. (1998). The overspent American: Upscaling, downshifting and the new consumer. Basic Books.

Slavin, R. E. (2017). Instruction based on cooperative learning. In R. Mayer \& P. Alexander (Eds.), Handbook of research on learning and instruction (pp. 388-404). Routledge.

Smither, R. D., \& Houston, J. M. (1992). The nature of competitiveness: The development and validation of the competitiveness index. Educational and Psychological Measurement, 52(2), 407-418. https://doi.org/ 10.1177/0013164492052002016

Sommet, N., \& Elliot, A. J. (2017). Achievement goals, reasons for goal pursuit, and achievement goal complexes as predictors of beneficial outcomes: Is the influence of goals reducible to reasons? Journal of Educational Psychology, 109(8), 1141-1162. https://doi.org/10.1037/edu0000199

Sommet, N., Elliot, A. J., Jamieson, J. P., \& Butera, F. (2019). Income inequality, perceived competitiveness, and approach-avoidance motivation. Journal of Personality, 87(4), 767-784. https://doi.org/10.1111/ jopy. 12432

Sommet, N., Morselli, D., \& Spini, D. (2018). Income inequality affects the psychological health of only the people facing scarcity. Psychological Science, 29(12), 1911-1921. https://doi.org/10.1177/09567976 18798620

Sommet, N., Pillaud, V., Meuleman, B., \& Butera, F. (2017). The socialization of performance goals. Contemporary Educational Psychology, 49, 337-354. https://doi.org/10.1016/j.cedpsych.2017.03.008

Sommet, N., Pulfrey, C., \& Butera, F. (2013). Did my M.D. really go to University to learn? Detrimental effects of numerus clausus on self-efficacy, mastery goals and learning. PLoS ONE, 8(12), e84178. https://doi .org/10.1371/journal.pone.0084178

Spence, J. T., \& Helmreich, R. L. (1983). Achievement-related motives and behaviors. In J. T. Spence (Ed.), Achievement and achievement motives: Psychological and sociological approaches (pp. 10-74). Freeman.

Stanne, M. B., Johnson, D. W., \& Johnson, R. T. (1999). Does competition enhance or inhibit motor performance: A meta-analysis. Psychological Bulletin, 125(1), 133-154. https://doi.org/10.1037/0033-2909.125.1.133

Sutter, M., Bosman, R., Kocher, M. G., \& van Winden, F. (2009). Gender pairing and bargaining-Beware the same sex! Experimental Economics, 12(3), 318-331. https://doi.org/10.1007/s10683-009-9217-9

Tassi, F., \& Schneider, B. H. (1997). Task-oriented versus other-referenced competition: Differential implications for children's peer relations. Journal of Applied Social Psychology, 27(17), 1557-1580. https://doi.org/10 $.1111 / \mathrm{j} .1559-1816.1997 . t b 01613 . x$

Tauer, J. M., \& Harackiewicz, J. M. (1999). Winning isn’t everything: Competition, achievement orientation, and intrinsic motivation. Journal of Experimental Social Psychology, 35(3), 209-238. https://doi.org/10 .1006/jesp.1999.1383

Tenenbaum, H. R., Winstone, N. E., Leman, P. J., \& Avery, R. E. (2020). How effective is peer interaction in facilitating learning? A meta-analysis. Journal of Educational Psychology, 112(7), 1303-1319. https://doi .org/10.1037/edu0000436

Thielmann, I., \& Hilbig, B. E. (2014). Trust in me, trust in you: A social projection account of the link between personality, cooperativeness, and trustworthiness expectations. Journal of Research in Personality, 50, 61-65. https://doi.org/10.1016/j.jrp.2014.03.006 
Thornton, B., Lovley, A. M., Ryckman, R., \& Gold, J. A. (2009). Playing Dumb and Knowing it All: Competitive Orientation and Impression Management Strategies. Individual Differences Research, 7(4), 265-271.

Thornton, B., Ryckman, R. M., \& Gold, J. A. (2011). Competitive orientations and the Type A behavior pattern. Psychology, 02(05), 411-415. https://doi.org/10.4236/psych.2011.25064

United Nations. (2020). Inequality - bridging the divide.

UNU-WIDER. (2021). World Income Inequality Database. WIID.

Vansteenkiste, M., Smeets, S., Soenens, B., Lens, W., Matos, L., \& Deci, E. L. (2010). Autonomous and controlled regulation of performanceapproach goals: Their relations to perfectionism and educational outcomes. Motivation and Emotion, 34(4), 333-353. https://doi.org/10 .1007/s11031-010-9188-3

Walasek, L., \& Brown, G. D. (2015). Income inequality and status seeking: Searching for positional goods in unequal U.S. States. Psychological Science, 26(4), 527-533. https://doi.org/10.1177/0956797614567511

Walasek, L., \& Brown, G. D. (2016). Income inequality, income, and internet searches for status goods: A cross-national study of the association between inequality and well-being. Social Indicators Research, 129(3), 1001-1014. https://doi.org/10.1007/s11205-015-1158-4

Walasek, L., Bhatia, S., \& Brown, G. D. (2018). Positional goods and the social rank hypothesis: Income inequality affects online chatter about high-and low-status brands on Twitter. Journal of Consumer Psychology, 28(1), 138-148. https://doi.org/10.1002/jcpy.1012

Wang, Z., Jetten, J., \& Steffens, N. K. (2020). The more you have, the more you want? Higher social class predicts a greater desire for wealth and status. European Journal of Social Psychology, 50(2), 360-375. https://doi.org/10.1002/ejsp.2620

Wei, W. (2017). A Critical Review of Washback Studies: Hypothesis and Evidence. In R. Al-Mahrooqi, C. Coombe, F. Al-Maamari, \& V.
Thakur (Eds.), Revisiting EFL assessment: Critical perspectives (pp. 49-67). Springer International Publishing. https://doi.org/10.1007/978 -3-319-32601-6_4

Weiss, M. R., \& Stuntz, C. P. (2004). A little friendly competition: Peer relationships and psychosocial development in youth sport and physical activity contexts. In M. R. Weiss (Ed.), Developmental sport and exercise psychology: A lifespan perspective (pp. 165-196). Fitness Information Technology.

Wilkinson, R. G. (1997). Comment: Income, inequality, and social cohesion. American Journal of Public Health, 87(9), 1504-1506. https://doi .org/10.2105/AJPH.87.9.1504

World Bank. (2020). Secondary education, pupils. https://data.worldbank .org/indicator/SE.SEC.ENRL?end=2019\&start=2000). WorldBank

Xiong, Y., So, H.-J., \& Toh, Y. (2015). Assessing learners' perceived readiness for computer-supported collaborative learning (CSCL): A study on initial development and validation. Journal of Computing in Higher Education, 27(3), 215-239. https://doi.org/10.1007/s12528-015-9102-9

Yamakawa, T., Okano, Y., \& Saijo, T. (2016). Detecting motives for cooperation in public goods experiments. Experimental Economics, 19(2), 500-512. https://doi.org/10.1007/s10683-015-9451-2

Zeneli, M., Thurston, A., \& Roseth, C. (2016). The influence of experimental design on the magnitude of the effect size-peer tutoring for elementary, middle and high school settings: A meta-analysis. International Journal of Educational Research, 76, 211-223. https://doi .org/10.1016/j.ijer.2015.11.010

Received June 13, 2021

Revision received November 24, 2021 Accepted November 30, 2021 